\title{
Christina TANIS
}

Université Européenne de Saint-Pétersbourg

\section{Du film allemand au documentaire soviétique : un dossier d'archive sur Gebeimnis Tibet}

\section{Le Tibet}

Correspondance avec le studio Gorki sur le doublage du documentaire allemand Le Tibet. 29.09.1948 - 9.11.1948. 32 p. (dossier conservé aux Archives d'État de la littérature et de l'art - RGALI -, f. 2456, op. 1, d. 2095 ; l'auteure de cette publication a traduit ce dossier d'archive, comprenant la note explicative, les cartons pour le film, la liste des séquences et le texte du commentaire sonore. Elle le commentera en seconde partie de l'article).

\subsection{Note explicative sur le « remontage » du film Le Tibet}

Le secret du Tibet, une production allemande du studio UFA de 1940, se présente sous la forme d'un film à paysages à caractère ethnographique ${ }^{1}$, construit à partir des matériaux documentaires que l'expédition allemande d'Ernst Schäfer avait tournés au Tibet en 1938-1939.

Toutlemontagedufilmétaitconstruitpourl'essentielautourdel'histoiredecevoyage, montrant la route, la vie, l'équipement et la vie de l'expédition vers le Tibet et au Tibet. Le

1 «Etnografičeski-vidovaja lenta » en russe, traduction presque littérale de Landschaftsfilm (note de la traductrice). 
film avait clairement tendance à opposer les participants de l'expédition, représentants de la race "supérieure », et le peuple ignorant et illettré du Tibet. La majorité des séquences du film souffrait de longueurs et d'un naturalisme superflu, propres au cinéma allemand. Au contraire, des éléments ethnographiques essentiels (habitations, ustensiles, costumes, ressources naturelles etc..) n'apparaissaient pas dans le film. Quelques séquences étaient accompagnées d'une musique très ennuyeuse, inexpressive et monotone.

Dans le texte des commentaires en voice over, l'attention était portée principalement sur la description du voyage, l'équipement, la vaillance des participants, alors que des renseignements ethnographiques et historiques sur le Tibet peu significatifs étaient présentés d'un point de vue pro-fasciste et tendancieux. Il est évident qu'une telle conception du film était inacceptable et ce dernier fut donc l'objet d'un nouveau montage.

Le remontage a éliminé du film les séquences relatives à l'historique de l'expédition, à la vie et à l'équipement des participants etc. On a coupé les passages montrant la progression interminable des voyageurs allemands à travers l'Himalaya et dans les steppes du Tibet sous le drapeau fasciste, ainsi que leurs camps et leurs distractions.

Dans la majorité des séquences restantes, les plans qui s'attardent complaisamment sur les recherches "raciales 》 des scientifiques allemands, qui mesurent les crânes, les mains et les pieds d'aborigènes ont été éliminés, ainsi que des séquences sur le comportement des Allemands vis-à-vis de la population locale.

Dans la plupart des autres séquences, on a coupé les longueurs excessives et les détails trop naturalistes (les séquences : chemin vers le Tibet, chèvres de montagne, enterrement des Tibétains etc.). Les coupes ont donné un rythme plus correct et plus dynamique (séquences des fêtes tibétaines) aux séquences dont l'exposition était un peu trop longue.

Le nouveau montage du film est fondé sur le principe d'un récit logique sur le Tibet. Il décrit successivement la position géographique du Tibet, la route vers le Tibet par l'Himalaya, la flore et la faune, le climat et la population du Tibet. Le film parle de la subordination de tout le pays au culte religieux, des monastères et de leur vie quotidienne, des monuments culturels du Tibet, des activités de la population (agriculture, élevage des moutons, artisanat), des rites. Il décrit la capitale du Tibet, Lhassa, son architecture, la fête du Nouvel An, les célébrations religieuses, les divertissements et les danses populaires, le défilé militaire et le carnaval.

L'écrivain V. Katanian a écrit des commentaires en voice over où l'on attire l'attention du spectateur sur la structure socio-économique et politique du Tibet, où l'on dévoile le rôle du bouddhisme et la théocratie qui règne au Tibet.

On donne une forme plus dynamique et plus agréable à l'oreille à l'accompagnement musical grâce à la compilation, au raccourcissement et au déplacement des séquences. 
Le métrage original du film était de $2800 \mathrm{~m}$, la version modifiée fait $1500 \mathrm{~m}$.

Le titre du film, Le secret du Tibet, a été changé pour Le Tibet.

S. A. Tokarev, professeur de l'Université ethnographique de l'Académie des Sciences de l'URSS, a été consulté quant aux coupes du film et à la nouvelle rédaction du commentaire.

Le chef de section de scénario: Schneiderman

Le chef du sous-titrage du film: Kolodny

Réalisateur - V. Sukhobokov

21.09.1949.

\subsection{Les cartons pour le fllm}

1. Le Tibet (créé à partir d'actualités étrangères)

2. Doublage en russe

Réalisateur - V. Sukhobokov

Ingénieur du son - N. Pisarev. 


\subsection{Liste des séquences du film}

Le Tibet avec la nouvelle musique $1500 \mathrm{~m}$ (+/- 55 minutes)

$1^{\text {ire }}$ partie :

Description géographique du Tibet

Sentiers de la montagne et des

broussailles - 1 minute 30 secondes

Réparation du pont - 1 minute 15 secondes

Passage - 2 minutes 10 secondes

40 secondes

Faune

Montagnes, glaciers

$2^{e}$ partie :

Oiseaux rapaces - 35 secondes

Kiangs - 1 minute

Yaks

Habitants du Tibet - 30 secondes

Moines et masques - 2 minutes 35 secondes

Monastères

Moines

Imprimerie - 30 secondes
Geheimnis Tibet (Le secret du Tibet 1943).

Version originale. $2800 \mathrm{~m}, 100$ minutes 45 secondes ${ }^{2}$ ]

Description géographique du Tibet 2 minutes 20 secondes [Ces scènes ont été gardées]

Présentation des participants de l'expédition 1 minute 20 secondes [Enlevé] Voyage au Tibet de l'Inde à travers l'Himalaya 2 minutes 18 secondes [Enlevé]

Sentiers de montagne et broussailles - 1 minute 30 secondes [gardé] Réparation du pont -3 minutes 50 secondes [partiellement gardé]

Danse sacrée -6 minutes 10 secondes [Enlevé] Assassinat de la bête mystique 3 minutes [Enlevé]

Oiseaux rapaces - 2 minutes 40 secondes [partiellement gardé]

Mesures anthropométriques 6 minutes 30 secondes [Enlevé]

Faune -3 minutes [partiellement gardé] Montagnes - 3 minutes 25 secondes [partiellement gardé]

Représentants du gouvernement tibétain 2 minutes [Enlevé]

Yaks et chevaux -2 minutes 05 secondes [partiellement gardé]

Kiangs - 1 minutes 12 secondes [partiellement gardé]

Cheminement de l'expédition - 1 minute 20 secondes [Enlevé]

2 Réalisé à partir de la version visionnable sur <https://youtu.be/HskdtYx_MCI> (document en ligne, consulté le 18.07.2016). 
$3^{e}$ partie :

Laboureurs et grues - 1 minute 30 secondes

Moutons et tapis - 2 minutes 5 secondes

Dans la rue en ville - 1 minute 5 secondes

Repas de riches - 40 secondes

Repas de pauvres - 30 secondes

Châtiment d'un pauvre

4 partie :

Enterrement - 2 minutes 15 secondes

«Lhassa est devant 》- 35 secondes

Pèlerins - 1 minute 40 secondes

Potala, architecture

Moine-prophète - 40 secondes

Camp en banlieue - 20 secondes
Habitants du Tibet - 1 minute 25 secondes [partiellement gardé]

Repas de pauvres -30 secondes [gardé]

Cheminement de l'expédition 3 minutes [Enlevé]

Ruines anciennes -2 minutes 30 secondes

[Enlevé]

Enterrement -3 minutes 30 secondes

[partiellement gardé]

Moines et masques -1 minutes 50

secondes [partiellement gardé]

Monastères - 2 minutes [gardé]

Moines - 1 minute 35 secondes [gardé]

Imprimerie - 35 secondes [partiellement

gardé]

Défilé militaire au carnaval - 2 minutes 55 secondes [partiellement gardé]

Moutons et tapis -3 minute 05 secondes

[partiellement gardé]

Cheminement de l'expédition 3 minutes 25 secondes [Enlevé]

Laboureurs et grues -1 minute 30 secondes [gardé]

«Lhassa est devant »- 35 secondes [gardé]

Pèlerins - 1 minute 40 secondes [gardé]

Potala, architecture -1 minute 55

secondes [gardé]

Cadeaux pour participants de l'expédition 5 minutes 20 secondes [Enlevé]

Châtiment d'un voleur - 30 secondes [gardé]

Dans la rue de la ville - 1 minute 30 secondes [partiellement gardé] Moine- prophète -40 secondes [gardé] Camp en banlieue -6 minutes 55 secondes [partiellement gardé] 
Du film allemand au documentaire soviétique ...

$5^{e}$ partie :

Sortie des dignitaires - 1 minute 20 secondes

Danse des lamas - 50 secondes

Expulsion du diable - 1 minute 10 secondes

$\sigma^{e}$ partie :

Défilé militaire au carnaval - 1 minute 55 secondes

Fin - 55 secondes

Total [de la musique] : 29 minutes 10 secondes
Tir à l'arc -3 minutes 10 secondes [partiellement gardé]

Danse des lamas - 1 minute 50 secondes [partiellement gardé]

Expulsion du diable - 1 minute 10 secondes [gardé]

Tir à l'arc - 55 secondes

Sortie des dignitaires -1 minute 20

secondes [gardé]

Cavalcade médiévale 3 minutes 40 secondes [Enlevé] 


\subsection{Texte du commentaire en voice over du film Le Tibet $^{3}$}

Le Tibet, le plus haut plateau du monde, se trouve au centre de l'Asie, caché derrière les plus hautes montagnes sur la Terre. Le territoire du Tibet est énorme $1200000 \mathrm{~km}^{2}$, plus que la France et l'Allemagne réunies.

Au nord et à l'est, le Tibet donne sur les provinces de l'ouest de la Chine; plus loin au nord, se trouvent la République Populaire Mongole et l'Union Soviétique; au sud et à l'ouest, il y a la frontière avec l'Inde himalayenne.

Officiellement, le Tibet fait partie de la Chine, mais en réalité il est contrôlé par un monarque autocrate, qui n'est pas soumis au gouvernement chinois, mais qui respecte en revanche la volonté de l'Angleterre.

De Calcutta - le plus grand port de l'Inde - aux frontières du Tibet, il n'y a que quelques centaines de kilomètres. Le fait de se trouver si près des plus riches possessions britanniques en Asie a déterminé le destin du Tibet. Les Britanniques s'inquiétant de la sécurité de leur empire colonial, ils essaient par tous les moyens de le contrôler. Pour soumettre le Tibet à leur influence, la main de l'impérialisme britannique s'étend donc au-delà de l'Himalaya. D'ailleurs, on sait qu'il y a de l'or au Tibet.

Le Tibet n'est accessible ni en train ni en voiture, ni en avion. Dans ce pays, il n'y a pas un seul kilomètre de chemin de fer, il n'y a pas de routes carrossables, il n'y a aucun aéroport. De tous les côtés, le Tibet est entouré de hautes montagnes et de déserts infranchissables. On ne peut pénétrer dans le pays qu'après avoir escaladé des sentiers de montagne et traversé des torrents dangereux sur des ponts suspendus.

La végétation des versants sud de la chaîne himalayenne est très variée : des arbres géants, des lianes, des fougères gigantesques. Il fait lourd dans la forêt comme dans une orangerie. L'air et la terre "fument» d'humidité. Sur les cimes des montagnes qui montent vers le ciel, à partir d'énormes glaciers primitifs, des rivières de glace s'écoulent. Il n'y a que des animaux très résistants, des mules et des ânes de race locale qui peuvent supporter des difficultés de ce dur pays.

Si un pont est détruit par une averse, il n'y a pas d'autre moyen que de le réparer soi-même car il n'existe pas d'autre passage. Les gens de la peuplade des Lepchas, qui habitent de l'autre coté de l'Himalaya, servent de guides et de porteurs. Ils sont obligés de réparer des ponts et de conserver la route en bon état. Sans eux, elle deviendrait rapidement impraticable.

Des fûts d'arbres liés et quelques branches et le pont est prêt!

Jusqu'à la prochaine averse...

La mise en page originale, qui multipliait les alinéas, a été modifiée. 
Le sentier grimpe de plus en plus haut.

Il faut ainsi monter jusqu'à une altitude de six mille mètres. Plus on monte, plus la nature devient hostile. Les derniers arbres se dressent à la limite des neiges éternelles - il s'agit de pins immenses agités par le vent. Dans les crevasses des rochers, on trouve les dernières fleurs. Et du coup, la vie se termine : où qu'on regarde il n'y a que des cimes enneigées.

Un col. Des glaciers se jettent dans des lacs de montagne isolés en glissant depuis d'énormes massifs montagneux. Ici, ils se transforment en coulées de glace. Durant la journée, les températures changent brusquement. Il est possible de traverser cette rivière sur la glace pendant la nuit et tôt le matin. Dans l'après-midi, la glace fond et il faut aller à la nage.

Et ce passage du sud vers le Tibet à travers la chaîne de l'Himalaya est considéré comme le plus facile! Le passage du nord par lequel les célèbres voyageurs russes Przewalski, Kozlov et Potanine partirent au Tibet, était le plus difficile.

Les premières créatures vivantes qu'un voyageur trouve au Tibet, sont les moutons bleus ${ }^{4}$ et les chèvres de montagne. Il faut prendre beaucoup de précautions et s'armer de patience pour ne pas effrayer les oiseaux en alerte. Mais si vous y arrivez, vous pouvez voir de près des rapaces géants, les Lemak et les Gimalayakaya. Ils se battent pour une proie. Les plus faibles se contentent de restes.

Le bruit des sabots de kiangs retentit dans des basses contrées. Ce sont des chevaux sauvages du Tibet. C'est l'un des plus beaux animaux des hauts plateaux d'Asie. Le troupeau obéit entièrement au meneur. Ainsi, sans effort, les kiangs couvrent de grandes distances. Un renard des steppes ferait mieux de ne pas rester sur leur chemin.

Les puissants yaks sont des animaux originaires du Tibet. Ces animaux forts à peau épaisse ne craignent rien, ni le froid rude, ni la tempête de glace. Leur long poil qui pend jusqu'à terre les protège contre le froid. Leurs pieds fourchus sont adaptés à l'escalade. Les yaks peuvent grimper les pentes comme des chèvres. Ils sont gentils et obéissants, mais il suffit de les charger pour qu'ils commencent à se mutiner. Formés en caravane, ils portent tranquillement leurs charges.

Les premières personnes qu'on croise sur la route, ce sont des nomades mendiants. Ils saluent le tout venant selon la tradition tibétaine. Ils font un salut et tirent la langue. Personne ne sait quel est le nombre exact d'habitants de ce pays. Selon certaines sources, ils sont 750 000, selon d'autres - il y en a 6000000.

Le Tibet est le seul pays au monde géré par des moines, pays où les rites religieux tiennent jusqu'à aujourd'hui une place significative dans la vie quotidienne. La religion bouddhiste pénétra ici à partir de l'Inde il y a douze siècles et, depuis, elle y règne sans partage. Des moulins à prière de toutes tailles tournent du matin jusqu'au 
soir. Chaque personne qui passe devant doit faire tourner ce moulin et prononcer l'incantation. Des pèlerins zélés répètent la même phrase absurde mille fois par jour.

Les moines représentent un tiers de la population masculine du Tibet. Des milliers d'entre eux sillonnent les routes du Tibet. Ils tournent des hochets de prière et marmottent des incantations. Ces lamas, comme on appelle les moines bouddhistes, s'installent au milieu de la route afin de faire un rite de prière. Les Tibétains croient qu'un lama est capable de combattre les démons et les mauvais esprits et de les soumettre à sa volonté, par des gestes symboliques et des attributs magiques comme un poignard, une hache et une sonnette magique.

Pour intimider le peuple, la religion bouddhiste dit que des mauvais esprits guettent l'homme tout au long de sa vie et après sa mort, jusqu'à ce qu'en fin de compte l'âme, après avoir fait une longue pérégrination, ne retrouve finalement le chemin du Royaume heureux de Bouddha.

Des idoles terribles et des masques monstrueux sont destinés à rappeler continuellement aux gens l'existence des mauvais esprits. Les gens doivent vivre dans la peur et prier sans cesse. Personne ne sait combien il y a de temples et de monastères au Tibet.

On les croise à chaque pas : qu'il s'agisse de petites chapelles et de temples ou bien de très grands monastères qui ressemblent à des villes. Des dizaines de dépendances entourent le temple du monastère. Parmi tous ces monastères, celui de Dachi-Khoumbo ${ }^{5}$ est considéré comme l'un des plus riches. Près de dix mille moines y résident. Pour l'État tibétain, des monastères si peuplés représentent une force considérable. Ils possèdent des terres et des pâturages et font souvent du commerce. Des milliers de paysans travaillent pour ces monastères dans des conditions de dépendance totale, en tant que serfs.

Dès le matin tôt, le son du gong convoque les moines à un office divin qui dure toute la journée. Le chant mélancolique du chœur des lamas retentit dans des cours. Le bredouillement sourd de l'exorcisme alterne avec ces chants. Deux fois par jour, les prières sont interrompues. Des serviteurs apportent du thé dans des lourdes cruches en cuivre.

Des jeunes membres de la communauté monastique portent le poids du travail quotidien. Des garçons de 6 à 10 ans s'accoutument à la vie monastique. Quand il y a trois fils dans une famille, l'un d'eux doit obligatoirement aller au monastère. C'est une coutume ancienne et les lamas exigent son respect d'une manière rigoureuse pour renforcer les monastères. En dehors des prières, le temps libre est consacré par les jeunes moines à produire des pilules médicinales composées d'herbes, de racines et de toutes sortes de poudres de perlimpinpin. L'action du gouvernement tibétain quant 
à la santé publique se limite à ces méthodes de charlatan. Les monastères publient aussi des livres.

L'écriture tibétaine existe depuis le VII siècle, mais l'art de l'imprimerie s'est figé au premier stade de son évolution : les caractères sont gravés sur des planches en bois et les épreuves sont faites à la main. Évidemment, tous les livres ont exclusivement un caractère religieux : il s'agit des textes bouddhiques sacrés. Le Kangyour - canon principal du dogme bouddhiste est composé de cent huit volumes.

Le bouddhisme a arrêté l'évolution politique et économique du Tibet au stade médiéval. La nature, avec ses montagnes impénétrables, a isolé le Tibet du monde extérieur. Mais plus encore que la nature austère du Tibet, ce sont des lamas qui, ayant pris tout le pouvoir dans leurs mains, empêchent le développement économique et culturel du peuple tibétain. La peur de perdre le pouvoir les pousse à tenir le peuple dans la plus profonde ignorance. Ils aspirent de toutes leurs forces à préserver l'isolement du pays et de son peuple.

L'accès à ce pays est fermé. C'est un pays sous clef. La Chine impériale qui avait jadis soumis le Tibet, soutenait les lamas dans leurs tentatives d'interdire toutes les influences externes et les échanges culturels. De même, l'impérialisme britannique qui fit irruption par la force au début du XXe siècle dans le territoire du Tibet, ne changea rien dans ce pays. Ses portes sont restées fermées. Il est avantageux pour les Britanniques de laisser l'économie du Tibet au niveau le plus bas pour que ses habitants soient pauvres, privés de droits et ignorants. On les tient ainsi plus facilement dans l'obéissance.

Le mode de vie, les usages, les coutumes, aussi bien que les relations économiques ont aussi peu changé au Tibet depuis des siècles que ces monuments de la culture tibétaine ancienne. La majorité des paysans est en position de servage absolu vis-àvis des monastères, de la noblesse locale et des princes. Ces derniers possèdent toutes les terres fertiles dans ce pays rigoureux. En travaillant dans des champs les paysans effectuent la corvée, ils paient des redevances en nature très importantes.

Il est difficile d'imaginer le niveau de misère dans lequel les paysans tibétains vivent. Ils travaillent la terre de la même manière qu'il y a mille ans.

[Apparemment, la grue qui visita des pays différents s'étonne. Elle avait vu comment on vivait, par exemple, pas loin d'ici, - en République populaire de Mongolie. $]^{6}$

De grands troupeaux de chèvres et de moutons pâturent dans des espaces infinis. Ils broutent des herbes maigres et raclent les racines du terrain. Si ces troupeaux avaient appartenu au paysan tibétain, ils auraient pu le nourrir et l'habiller. Mais ces troupeaux et ce terrain dans lesquels ils pâturent appartiennent aux monastères et 
aux féodaux. Le lainage dense et souple des moutons et des chèvres du Tibet est très apprécié.

Il est impossible de vivre dans le rude climat du Tibet sans vêtements chauds. L'hiver est long, sans neige, avec des températures qui descendent jusqu'à moins quarante. L'été est très court, avec des journées chaudes et des nuits froides. Bien que la technique de tissage soit encore primitive, les tapisseries locales se distinguent par leurs couleurs et leurs ornements pittoresques. Les maisons sont construites en pierre brute. À la place de la chaux, on utilise de l'argile humide. Les maçons ne se hâtent pas. Ils doivent avant tout chasser les mauvais esprits présents sur le lieu de travail à l'aide de chansons et de prières.

Pratiquement toute la vie urbaine se déroule dans la rue devant des maisons. Les petits artisans s'occupent de leur travail : les forgerons forgent des fers à cheval, les chaudronniers réparent des ustensiles, les cordonniers font des chaussures. La population urbaine vit dans la misère et à l'étroit, comme tout le peuple tibétain. Ici même, dans ces ruelles, ils font la cuisine et mangent leur repas frugal.

La spécialité nationale est la Tsampa. C'est un thé avec du beurre, du sel et de la farine d'orge grillée. Évidemment, tout le monde ne mange pas ce repas maigre. En plus de la Tsampa traditionnelle, les maîtres de ce pays mangent d'autres choses. Ça se voit sur leurs visages contents. Si une femme d'une famille pauvre se permet de battre un peu de beurre pour les siens - il s'agit d'une grande fête de famille. Ses enfants ne s'éloignent pas d'elle.

C'est ainsi que les gouverneurs tibétains rendent la justice vis-à-vis de ceux qu'ils considèrent comme des délinquants. Ce sont des pauvres. Les riches se rachètent de toutes les peines. Dans quelques jours, ces gens-là seront jetés en prison, mais pour le moment leurs parents peuvent encore les nourrir.

Selon la doctrine bouddhique, les corps des défunts doivent être entièrement incinérés. Mais le bois tibétain est très cher, il n'y a pas de charbon du tout, et la religion fut obligée de s'adapter. Les dépouilles des morts sont jetées en tant que nourriture aux milans qui passent ici pour des oiseaux sacrés. Sur un accompagnement permanent de prières, les corps sont coupés en morceaux et les ossements sont concassés, pour que des oiseaux puissent terminer tous les restes. Ensuite, un lama fait signe et des milans commencent se réunir.

La ville de Lhassa est la capitale du Tibet. Ici habite le Dalaï-lama, le régent suprême du Tibet. Ici sont établis sa cour et ses ministres. Les Tibétains estiment que Lhassa est une ville sacrée. Chaque croyant considère comme une bénédiction d'avoir fait le pèlerinage vers les lieux saints de Lhassa au moins une fois. Quand les pèlerins atteignent ces sommets ils s'exclament: "Lhassa est devant!" .

Ils suspendent aux arbres et aux buissons des deux côtés de la route des chiffons, des rubans et des morceaux de papier avec des exorcismes et des prières écrits 
dessus. C'est comme ça que les pèlerins demandent la bénédiction des dieux avant de continuer leur chemin.

La file des croyants se déroule et se traîne en direction des murailles de la ville sacrée. Des pèlerins zélés mesurent le chemin vers Lhassa par leurs propres corps : ils tombent, bras étendus, ils se lèvent, ils ne font que deux pas pour se prosterner du nouveau. Donc, si on tombe et se lève mille fois, on ne fera que deux kilomètres par jour. En atteignant les murailles de la ville et en les contournant plusieurs fois, des pèlerins passent d'un objet sacré à l'autre. Il faut de nouveau se jeter à terre, se relever ensuite et se prosterner encore. Ça dure pendant des heures. Ici, la surface de la pierre brille à force d'usure. Des pèlerins affluent à Lhassa de tous les côtés du pays, à cheval et à pied. Plusieurs d'entre eux arrivent notamment pour la fête du Nouvel An, célébrée au Tibet le 15 février.

Enfin, devant les yeux des pèlerins apparaît le lieu le plus sacré de cette ville bouddhique la plus "sacrée " : il s'agit du monastère et du palais du Potala c'est la résidence du Dalä̈-Lama, le régent suprême du Tibet. C'est là qu'il habite et c'est d'ici qu'il gouverne le pays. Les Tibétains considèrent Dalaï-lama comme l'incarnation d'une des divinités bouddhiques les plus élevées. La religion dominante affirme cette idée et l'inculque infatigablement aux croyants. Tout le pouvoir d'État tibétain appartient au Dalaï-lama. C'est un roi et un dieu en même temps, et rien ne limite son autocratie. Sauf les Anglais, évidemment.

Le Palais est très beau. Il fut construit en pierre de taille et en brique, il fait trois cents mètres de long. La partie centrale est rouge, toutes les autres sont blanches. Ses toits scintillent d'or. Plusieurs bâtiments se trouvant au pied de la colline appartiennent au Palais. Ce sont des dépendances, des greniers, des écuries, des locaux destinés à la garde. À juste titre, le peuple tibétain peut être fier de cette bâtisse remarquable érigée il y a trois cents ans. Ce monument grandiose de l'architecture tibétaine témoigne de l'art de construction et du goût artistique de ce peuple opprimé depuis des temps immémoriaux.

Les fêtes du Nouvel An durent pendant trois semaines. Ces jours-là Lhassa est bondée de pèlerins et se transforme en un gigantesque temple. Du matin jusqu'au soir tard, des gens s'attroupent dans les rues en flânant de-ci de-là. Des moines prophètes errants apparaissent. Pour une petite pièce, ils se mettent à prédire l'avenir. En temps normal la ville de Lhassa ne compte que vingt mille habitants. Mais aujourd'hui la ville reçoit cinquante à soixante mille personnes. Ceux qui ne trouvent pas de refuge intra-muros, montent des tentes dans les champs.

Dans l'attente $d u$ début de la fête, des musiciens ambulants et des vendeurs amusent les nouveaux venus. Le thé pour la Tsampa se prépare dans des grandes chaudières en cuivre. Des trompettes sonnent le début de la fête. Des chevaux sans cavaliers galopent dans des rues de la ville. 
Les Tibétains croient que ce sont les dieux équestres qui entrent à Lhassa. Des ministres et des dignitaires vêtus en costumes luxueux de soie apparaissent sur la place des festivités. Ils prennent place dans l'une des tentes les plus luxueuses, en se présentant comme les substituts de Dalaï-lama. Les hauts fonctionnaires reçoivent des serviettes blanches : selon la vieille coutume du Tibet c'est un signe de respect et d'humilité. Des lamas sortent du portail d'un temple sacré dans une procession solennelle. Ce sont des lamas les plus importants et les plus pieux. On ne peut pas commencer la fête sans eux. L'un de canons fondamentaux de la foi bouddhique annonce : "Il est impossible d'avoir le salut sans lama ».

La foule fixe son attention sur la procession et les danses rituelles. La mise en scène des rites religieux est le moyen de prédilection des lamas pour influencer la conscience du peuple. Les lamas détournent l'attention du peuple d'une réalité peu attrayante. La danse guerrière d'une des tribus sud est exécutée avec une grande maîtrise. Pour interpréter leur danse, les lamas utilisent des masques effrayants. Ces masques personnifient les dieux menaçants du bouddhisme terrassant les ennemis de la foi.

Une place est réservée pour les danses masquées consacrées à la fin de l'année qui part. Un autre détachement de lamas descend sur la place. Derrière eux, accompagné du son de trompettes et de cris de la foule, un homme est porté, dévoré par des démons installés dans son âme selon les convictions des lamas. L'entière responsabilité des péchés commis par le peuple l'année précédente est conférée par les lamas à cet homme. Et cet homme doit être chassé de la ville.

Enfin les cérémonies religieuses s'achèvent. Maintenant c'est le tour d'autres festivités du Nouvel An. La vraie fête populaire commence. Les Tibétains utilisent le bois le plus souple afin de créer des arcs pour tirer au but. Il faut viser dans le centre du cercle en bois. Évidemment, ce tireur-là n'aura pas de prix... Tirer à cette distance demande une grande maîtrise. On tire également sur des cibles en plein galop, en utilisant des arcs et des fusils. Les meilleurs danseurs venus de tous les coins du pays exécutent une danse nationale dans un tourbillon sauvage.

Une nouvelle procession attire l'attention de la foule. En tête de la troupe, il y a des généraux. Ils portent les anciens uniformes rutilants des chefs de guerre tibétains. Ils sont suivis par des guerriers revêtus d'armures médiévales et armés de lances, d'épées et de mousquets anciens. Cette procession fait trois fois le tour du temple sacré. Bien sûr, ce n'est qu'un carnaval. Les véritables troupes militaires du Tibet ne participent pas à la fête. Elles ne ressemblent pas du tout à des troupes médiévales.

Les uniformes britanniques portés par les soldats tibétains montrent d'une manière évidente qui donne les ordres en réalité. Des officiers tibétains ont appris les règles de l'art militaire contemporain au service militaire britannique en Inde. Maintenant ils apprennent à leurs compatriotes ce que les Anglais leur ont appris. Du point de 
vue du développement politique et économique, le Tibet actuel est peut-être le pays le moins civilisé au monde.

Soumis par les lamas il y a plusieurs siècles, le peuple tibétain vivait et vit dans des conditions d'une misère noire. Et ses gouvernants savent que leur pouvoir sera fort tant qu'ils peuvent garder le peuple dans l'état d'ignorance et de servitude où il se trouve actuellement. Les gouvernants du Tibet le font avec l'autorisation suprême de leurs terribles dieux et sous la protection de l'impérialisme britannique.

20.09.1948.

\section{Analyse des documents d'archive}

Les documents traduits ci-dessus montrent l'usage soviétique du documentaire allemand Le secret du Tibet (Geheimnis Tibet, 1943) et les coupes qui ont été faites dans le film. Le secret $d u$ Tibet fut confisqué à l'Allemagne en 1945 puis modifié. À partir de 1948, il fut distribué pendant trois ans sur le marché soviétique ${ }^{7}$, parmi d'autres films du Reichsfilmarchiv qui avaient été saisis par les Soviétiques dans les territoires conquis lors de la Seconde Guerre mondiale. L'histoire de ce film en URSS est un bon exemple de l'exploitation soviétique des films trophées (trofejnoe kino).

Rappelons que ces films confisqués furent présentés dans tous les cinémas soviétiques entre 1946 et 1957, comme également des productions françaises, italiennes et américaines. Au total, 150 films étrangers furent distribués dans les salles soviétiques. Si les films américains étaient projetés dans des clubs d'ouvriers et de syndicats (dites salles «fermées ») sans licence en vertu de l'alliance de l'URSS et les États-Unis au cours de la Seconde Guerre mondiale, les films allemands étaient au contraire lancés en masse sur le marché soviétique dans tous les cinémas (dites salles « ouvertes ») au titre des réparations (Pozner 2012 : 84-95 ; Kenez 1992 ; Taylor 1979).

Nous tenterons ici de retracer le contexte politique, idéologique, social et culturel du remontage et de la diffusion du film Le secret du Tibet, devenu simplement Le Tibet en URSS.

Les rushes originaux furent tournés pendant la fameuse expédition SS menée au Tibet, en 1938-1939, sous la direction d'Ernst Schäfer. Cette expédition avait pour objectif la scrupuleuse analyse anthropométrique et craniologique des Tibétains ainsi que l'exploration météorologique, zoologique et géologique du pays. Dans le film, la propagande de l'idéologie nazie et de l'impérialisme allemand étaient cependant trop explicites, ce qui demanda des modifications profondes du film avant sa sortie 
dans la distribution soviétique : il fut réduit, une nouvelle musique fut créée et des commentaires en voice over furent ajoutés. C'est le caractère radical des coupes censoriales qui initia tout un dossier aux Archives d'État de la littérature et de l'art (RGALI) publié dans cet article.

\subsection{Censure soviétique par rapport aux films trophées}

Le secret $d u$ Tibet est un exemple des transformations les plus radicales subies par les films trophées. La distribution de ce film comme de tous les autres films trophées fut déterminée par des raisons économiques. Après la Seconde Guerre mondiale, dans l'industrie du cinéma soviétique avait débuté l'époque dite du "manque de films » (Epoha malokartin'ja), où le Comité du cinéma avait réalisé « moins de films mais de meilleure qualité » (Letopis' rossijskogo kino. 1946-1965 2010 : 89-90). Néanmoins comme le Comité central avait fait devoir au Comité du cinéma de remplir un plan de recettes, l'exploitation des films trophées aidait le Comité du cinéma à alimenter son budget. En choisissant les films, les autorités soviétiques marquaient donc leur préférence pour des genres divertissants (mélodrames, opérettes, biographies et films d'histoire) qui n'avaient aucun message idéologique, mais dont on attendait de bonnes recettes.

Cependant, les films anti-britanniques du $\mathrm{III}^{\mathrm{e}}$ Reich représentent un cas particulier car ils furent réutilisés pour leur propos, tout en étant adaptés aux nécessités de la politique internationale soviétique. Ainsi les films Der Fuchs von Glenarvon (Le Renard de Glenarvon, Max W. Kimmich, 1940), Ohm Krüger (Oncle Krüger, Hans Steinhoff, 1941 avec Emil Jannings) ou Kautschuk (Marajo, la lutte sans merci, Eduard von Borsody, 1938) furent projetés dans le contexte de la guerre froide. Valérie Pozner remarque que, dans la version originale à la fin du film Ohm Krüger, le protagoniste espère que « un jour, des peuples grands et puissants se dresseront contre la tyrannie britannique et anéantiront l'Angleterre. Dieu sera à leurs côtés. Et la voie sera ouverte vers un monde meilleur ». En supprimant la référence à Dieu, c'était un discours qui pouvait presque passer pour soviétique en 1949 ou 1950 (Pozner 2012 : 93). Le doublage rendait cette adaptation indécelable. Du coup, la ressemblance entre les régimes nazi et soviétique devenait frappante de l'extérieur comme le notait le journal ouest-allemand $Z i^{8}$ dans l'article La méthode simplifiée en 1949 :

Rentrés de captivité en URSS, des prisonniers de guerre allemands racontent, selon DENA, que le film national-socialiste de propagande Ohm Kruger est projeté en Biélorussie soviétique dans une version synchronisée, et ce depuis la fin de la guerre jusqu'aujourd'hui, et, d'après eux, avec succès. Nous nous causons du tourment au sujet du Juif Süss et de Veit Harlan, nous nous donnons de la peine pour réhabiliter

Journal anti-soviétique du secteur britannique de Berlin. 
des nazis, et tout cela en pure perte ; et maintenant le Kremlin nous montre comment il faut faire. [...] Tous les ex-stars à la botte de Goebbels peuvent se considérer comme réhabilitées. La méthode est très simple : celui qui fait de la propagande contre «des fauteurs de guerre impérialistes» est de notre côté ; celui qui est de notre côté est antifasciste ; et celui qui est anti-fasciste ne peut pas être nationaliste. Emil Jannings, acteur principal de ce film, hésita à émigrer en Amérique du Sud, parce que le titre de «l'artiste émérite de l'Union soviétique» est presque aussi beau que celui «d'artiste d'Etat»?.

Après la publication de cet article (publication si bien remarquée par les autorités soviétiques qu'elles la firent traduire et l'archivèrent), le mandataire du Sovexportfilm, Usoltsev, demanda à Bolchakov de « donn[er] des directives au Glavkinoprokat pour que les camarades distribuent prudemment les soi-disant films «trophées» et qu'ils nous demandent chaque fois des renseignements sur l'équipe de tournage pour éviter des attaques indésirables $»^{10}$.

À la lumière de cette directive de la distribution, Le secret du Tibet a un statut spécifique. Le film de propagande nazi devient, après le remontage, un film ethnographique chargé d'idéologie soviétique. Tous les films trophées étaient d'abord soumis au "remontage » et ensuite doublés ou sous-titrés. Ainsi, les Soviétiques procédaient à la coupure de certaines scènes à caractère religieux, mystique ou érotique, peu conformes à l'idéologie soviétique. Les films trophées étaient en particulier rigoureusement expurgés des motifs nazis. Par exemple, dans le film Die letzte Runde (Le dernier round, Werner Klingler, 1940) distribué sur les écrans soviétiques en 1949, les passages sur l'éducation d'un boxeur allemand nazi furent enlevés du film $^{11}$. En 1948, on fît même des tentatives pour modifier Jud Süß (Le Juif Süss, Veit Harlan, 1940) dans le nouveau contexte de la campagne contre les « Cosmopolites » commencée dans les années 1946-1948 (Pozner 2012 : 90). Cependant le public n'appréciait pas en général l'image positive des Allemands dans les films trophées. Par exemple, un militaire nommé Gusev écrivit à la rédaction du journal Literaturnaïa gazeta : « On comprend que des films allemands provoquent l'indignation. [...] c'est comme si l'ennemi d'hier avait charmé les spectateurs soviétiques $»^{12}$. Sous cet aspect, il faut citer la lettre d'une spectatrice sur le film allemand Die Mörder sind unter uns (Les Assassins sont parmi nous, Wolfgang Staudte, 1946), même si ce film réalisé en zone d'occupation soviétique par la DEFA n'était pas un trophée. Elle écrivait :

11 Centralnyj Gosudarstvennyj Arhiv Literatury i Iskusstva Sankt-Peterburga (CGALI), f. 257 , op. 19 , d. $416,1.62$. 
Aujourd'hui, j'ai vu le nouveau film Les Assassins sont parmi nous et je suis indignée au point de ne pas pouvoir décrire mon émotion. Le film parle des «bons » Allemands, mais d'une part les personnages sont pas du tout convaincants et d'autre part il est trop tôt pour montrer nos ennemis du bon côté. [...] La guerre a mis fin à une vie heureuse, parfaite, aisée de notre peuple et a apporté tant de malheurs et d'horreurs ! Et deux ans après la fin de la guerre, on nous fait voir un film sur des bons Allemands. C'est inadmissible! Quand je vois une colonne d'Allemands dans la rue aller travailler, je les perçois comme des poux. C'est non seulement répugnant de les regarder, mais j'ai même envie de les tuer ${ }^{13}$.

Il n'est pas évident de reconstruire la perception contemporaine du phénomène des films trophées. Les lettres découvertes aux archives ne l'éclairent pas dans son intégralité, parce qu'elles appartiennent à des rapports officiels et sont pleines de critiques négatives et de propositions de projeter des films soviétiques à la place des films étrangers. Cependant, on peut supposer que la réaction négative des spectateurs était sincère.

Néanmoins, les films trophées devinrent tout de même un phénomène par l'influence qu'ils exercèrent sur toute une génération. Leur succès était énorme. Par exemple, le film Die Frau meiner Träume (La Jeune Fille de mes rêves, Georg Jacoby, 1944) fit 103900000 entrées en 1947. Selon M. Turovskaja « le succès de La Jeune Fille de mes rêves soulignait le manque aigu d'aisance, l'absence d'un standard de vie européen (même kitsch) et enfin cela soulignait l'absence de valeur érotique de la femme » en Union Soviétique (Turovskaja 2010 : 77, 87). Des mémoires d'aprèsguerre affirment que des films trophées servaient de moyen d'évasion pour toute une génération dont Marika Rökk devint la sex-symbol. Ainsi, l'actrice soviétique L. Gurtchenko se souvient que le film montrait « une vie tellement rose, sans nuages, avec de la musique, des plumes, des perruques poudrées, des chapeaux, des crinolines et des dentelles. Les gens avaient tellement besoin de beauté et de musique que tout le monde regardait ce film dix fois » (Gurčenko 2000 : 177). Ces films donnaient aux spectateurs ce qu'ils cherchaient : dans le cinéma soviétique, ces films palliaient le manque de divertissements; ils offrirent aux Soviétiques une évasion hors de la vie quotidienne.

Les pratiques de la censure appliquées aux films trophées s'attachaient à réduire la contradiction, terrible pour " la génération de vainqueurs », entre la rhétorique soviétique et le contre-modèle des films nazis. Un avant-propos idéologique devait orienter le spectateur vers les valeurs soviétiques et souvent cela s'opposait au contenu des films. Par exemple, le carton précédant le film Rembrandt (Hans Steinhoff, 1942. ill. 1,2) indiquait : 
Le réalisme sévère de ce maître génial ne fut pas compris et ne fut pas apprécié de ses contemporains. L'intransigeance créatrice de Rembrandt le mettra en conflit avec le milieu bourgeois. De nombreux envieux et des ennemis ruinèrent le peintre et le réduisirent à la misère. Mais ni les malheurs ni la persécution n'abattirent Rembrandt. En travaillant sans répit et avec enthousiasme jusqu'au jour dernier de sa vie il créa des chefs d'œuvre de la peinture.

Ces avant-propos furent introduits pour répondre aux questions des spectateurs soviétiques concernant la multiplication des films trophées. Les fonctionnaires du Comité du Cinéma se voyaient donc obligés de donner des explications. Le chef du Glavkinoprokat Kalachnikov était formel à la conférence des cinéastes des 15-17 janvier 1949 à Kiev :

Les camarades expriment une idée précise, ils se demandent comment répondre à une série de questions. Comme le montre la dernière diffusion en 1949, chaque film est précédé d'un avant-propos. Celui-ci, approuvé par les autorités compétentes, caractérise le contenu du film. [...] Après ces demandes d'explications nous avons décidé de rajouter les avant-propos qui pourraient aider à comprendre le message du film ${ }^{14}$.

Avant la sortie de tous les films identifiés comme « trophées » en URSS, les noms des créateurs ou acteurs étaient enlevés. Les films étaient rebaptisés et les images étaient précédées d'un carton d'introduction : « Ce film a été pris comme trophée après la défaite de l'armée soviétique des troupes nazies près de Berlin en 1945 », ce qui renvoyait le spectateur à la victoire récente. Le secret du Tibet n'a par contre pas été présenté au grand public comme un film trophée ou un film étranger. Le générique ne présentait que les créateurs soviétiques du film avec la mention "élaboré à la base d'actualités étrangères ». Le cas de Le secret $d u$ Tibet est donc unique au sens où cette œuvre perdit le statut anonyme d'un film trophée ou étranger et, après le « remontage », ce documentaire fut projeté comme un film national, présentant au générique une équipe soviétique.

\subsection{Remontage du flm et contexte politique}

Après le remontage, il n'y avait plus, dans la version modifiée, d'images évoquant l'impérialisme et les valeurs allemandes. L'histoire de l'expédition nazie, les mesures anthropométriques des tibétains, les négociations des participants de l'expédition avec le gouvernement tibétain : tout cela avait disparu. Comme l'expédition était placée sous le patronage de Himmler et financée en partie par l'Ahnernerbe (Société pour la recherche et l'enseignement sur l'héritage ancestral), les participants de l'expédition devaient, en dehors des objectifs « scientifiques », découvrir et recueillir des connaissances occultes et explorer le Tibet du point de vue de son rapport avec la 
race aryenne. L'expédition filma des rituels et des rites religieux. Comme ces scènes n'étaient pas compatibles avec la propagande soviétique, les images évoquant le mysticisme furent enlevées du film. Finalement, la trame générale fut défaite en ne conservant de l'original que les images de la flore et de la faune, du climat, de la population du Tibet et de leurs usages, de l'architecture de Lhassa. Le remontage orientait ainsi le film vers l'idéologie soviétique.

Pour mieux comprendre le montage et les modifications du film, il faut connaître le contexte politique de l'époque. Après la Seconde Guerre mondiale, la situation politique en Asie changea radicalement. En 1947, l'Inde reçut l'indépendance, et, en Chine, la guerre civile se déclencha en 1946 entre le Kuomintang et le Parti communiste, guerre qui tournera en faveur de ce dernier. Bien que le Tibet gardât officiellement son indépendance, les deux parties en conflit le considéraient comme une région de la Chine. Dans le contexte de guerre froide, l'URSS soutenait les projets de la Chine entre autres par crainte que « les impérialistes anglo-américains » puissent faire d'un Tibet indépendant une place d'armes anti-soviétique. La position de l'URSS envers le statut du Tibet est exprimée explicitement dans les pages de la Grande Encyclopédie soviétique en 1946 : «Selon la constitution chinoise le Tibet est une partie de la Chine [...] Actuellement, le Tibet a une autonomie interne sous la suzeraineté nominale de la Chine et sous l'emprise de l'Angleterre de facto » (Andreyev 2003 : 367-394). Cette position est reprise dans le commentaire soviétique du film où on dit que, « officiellement, le Tibet fait partie de la Chine, mais en réalité il est contrôlé par un monarque autocrate, qui n'est pas soumis au gouvernement chinois, mais qui respecte par contre la volonté de l'Angleterre ». Donc les Soviétiques reproduisent le modèle rhétorique anti-britannique de la version originale et les mêmes images au début du film, car celles-ci convenaient aussi à la propagande soviétique dans sa politique extérieure. Pour souligner les conséquences négatives de l'action de l'impérialisme britannique, le film se termine d'ailleurs par des images de l'armée tibétaine à qui les Anglais apprennent l'art militaire.

Cette tradition du remontage (la reconstitution des scènes par de nouvelles séquences avec comme résultat la réalisation d'un autre film) provient des années 1920, où elle est apparue comme le moyen de faire un certain compromis entre les impératifs du tiroir-caisse et ceux de l'idéologie. Le rétablissement de l'industrie cinématographique soviétique nécessitait des moyens financiers qu'il était possible de se procurer par la diffusion de films étrangers, ou prérévolutionnaires, qui étaient remontés en accord avec l'idéologie du nouveau pouvoir. Dans les années 1920, le remontage n'était pas seulement un élément de l'industrie cinématographique soviétique, mais aussi un aspect important de la culture cinématographique : le sujet était activement discuté dans la presse. La pratique était radicale et presque tous les cinéastes d'avant-garde (les frères Vassilev, Eisenstein, Choub, Koulechov) étaient passés par là et ils deviendraient célèbres par leurs expériences en la matière (Tsyvian 
2004 : 122-145). Dans ces années-là, le phénomène du remontage se développe à la mesure des discussions du LEF à propos du fait et du matériau au cinéma (Pozner 2006 : 91-104 ; Albera 2008 : 83-91). Les actualités filmées et le documentaire s'opposaient dans ce contexte à l'artificialité du cinéma de fiction, mais le montage pouvait être une « méthode d'analyse » comme dans les travaux d'Esther Choub. La cinéaste soviétique, avait créé une nouvelle méthode de compilation des actualités sans tourner de nouvelles séquences. Par exemple, dans son film La Chute de la dynastie des Romanov (1927), elle opposait des images où la plus haute aristocratie se mettait « en sueur » en dansant au bal, avec des images où les paysans, travaillaient dans les champs, eux aussi « en sueur» (ce carton était répété avant les séquences). Esther Choub démontra ainsi que des images montrées dans un autre contexte prenaient un autre sens. Néanmoins, en montant des images documentaires, Choub gardait une certaine neutralité en ne manipulant pas le matériau : d'après elle, les faits parlaient d'eux-mêmes. Dans la version soviétique du Tibet, les processus de remontage sont cachés alors que les scènes du film et leur contenu sont interprétés dans un but de propagande. En utilisant les images du film à leur gré, les Soviétiques en remodelaient le propos. Par exemple, la version originale évoque le châtiment des voleurs qu'on attachait au pilori en leur mettant au cou une planche. Dans la version soviétique, selon le schéma communiste critiquant une « justice de classe », on met l'accent sur le fait que c'est un pauvre qui est condamné injustement. C'est donc un élément à charge contre le régime théocratique du Tibet.

En URSS, dans les années 1940-1950, l'atmosphère d'amitié fraternelle et de coopération avec la Chine de Mao, créait une nouvelle vague d'intérêt pour le Tibet. Les journaux soviétiques parlaient beaucoup du Tibet dans le cadre de la guerre civile en Chine. Les œuvres de célèbres voyageurs russes au Tibet et en Asie centrale sont réimprimées à grand tirage ${ }^{15}$. Par exemple, dans les années 1947-1948 l'éditeur Geografgiz republie les livres de Przewalski et Kozlov, célèbres voyageurs au Tibet. Des œuvres sur le Tibet de chercheurs et de journalistes locaux et étrangers prosoviétiques sont également publiées. Notre film, distribué entre 1948 et 1951, faisait partie de cette politique culturelle.

\subsection{Conclusion}

En ce qui concerne les films trophées, le remontage et la projection du film nazi Le Secret $d u$ Tibet a un caractère assez spécifique. Comme tous les films trophées, il

15 Par exemple : Nikolaj Prževal'skij, Ot Kul'dži za Tjan'-Šan'i na Lob-nor, Moscou : Geografgiz, 1947. Nikolaj Prževal'skij, Iz Zajsana čerez Hami v Tibet i na verhov'je želtoj reki, Moscou : Geografgiz, 1948. Nikolaj Prževal'skij, Ot Kjahty na istoki želtoj reki : Issledovanie severnoj okrainy Tibeta i put'čerez Lob-Nor po bassejnu Tarima, Moscou : Geografgiz, 1948. Petr Kozlov, Mongolija i Kam : 3-letnee putešestvie po Mongolii i Tibetu (1899-1901 gg.), Moscou : Geografgiz, 1948. 
fut confisqué en Allemagne en 1945, modifié et lancé sur le marché soviétique en 1948. Néanmoins, à la différence des films trophées qui, après la censure soviétique, acquéraient un statut anonyme et préservaient leur structure de narration, Le Secret $d u$ Tibet fut modifié radicalement et ne présenta plus de signe de sa provenance. Il commençait par un générique créditant les cinéastes soviétiques, et après le remontage, il fut présenté comme un film soviétique "créé à partir d'actualités étrangères ». Bien que les scènes de la propagande en faveur des idées nazies et de l'impérialisme allemand eussent été enlevées de la version originale, il gardait un caractère idéologique. En remettant les séquences dans un autre ordre et en ajoutant un nouveau commentaire, les Soviétiques produisirent un documentaire ethnographique sur le Tibet, où ils critiquaient le régime théocratique du pays et l'impérialisme britannique. Le film exprimait explicitement la position de l'URSS contre l'indépendance du Tibet dans le cadre des changements géopolitiques en Asie et de la guerre civile en Chine. La projection de ce film sur le Tibet s'intégrait bien à la politique culturelle prévalant dans les années 1940-1950. Ainsi un film nazi saisi par les troupes soviétiques de l'Allemagne en 1945, transformé et distribué en URSS, pouvait ainsi être réorienté dans le sens de la propagande soviétique.

Le destin du film Le Tibet soulève plus largement des questions encore non résolues par les historiens du cinéma. La recherche concernant la censure soviétique et le remontage des films trophées est fondée sur deux types de sources archivistiques, d'une part les sources visuelles (les films trophées eux-mêmes) et d'autre part des sources écrites (ordres, notices explicatives, rapports sur les coupes pratiquées). Il est souvent impossible d'étudier l'un sans l'autre. Ainsi, en étudiant par exemple les corrections faites au montage grâce à une analyse comparée de la copie diffusée par les Soviétiques et de la version originale, on en vient à se demander ce qu'est l'original. Dans la mesure où les futurs films-trophées avaient été diffusés dans différents pays avant leur confiscation, non seulement ils étaient techniquement en mauvais état, mais ils existaient de plus en plusieurs versions résultant à chaque fois de coupures, d'un montage et d'un doublage différents. Dans ce cas, les archives écrites, si elles existent, peuvent être une source complémentaire quant à la reconstitution de l'histoire de la censure cinématographique soviétique et aux coupes pratiquées dans un film.

Le doublage et la traduction des films-trophées est un objet d'étude distinct. Certaines copies diffusées étaient doublées, d'autres sous-titrées. Il serait intéressant de savoir quelles parties des textes originaux étaient traduites et lesquelles ne l'étaient pas. Dans ce cas, il faut consulter les feuilles de montage des films-trophées telles qu'elles sont conservées au Gosfilmofond.

Le raccourcissement des films par l'élimination des « longueurs » est une autre spécificité du remontage des films dans les années 1940 et elles posent des questions qui touchent à la censure, à la politique de diffusion, mais aussi à l'esthétique cinématographique. On peut suivre ces coupures aussi bien en visionnant un film sur 
une table de montage qu'en analysant les rapports écrits sur le remontage. Il faudrait comprendre d'où vient cette volonté de rendre les films-trophées plus dynamiques en coupant des «longueurs », alors même que la dramaturgie cinématographique soviétique était loin d'être exempte de ce travers. La notice explicative du remontage du Secret du Tibet relève des longueurs et les Soviétiques y voient une spécificité culturelle nationale, «propre au cinéma allemand ».

Comme la version modifiée n'est conservée que sur un négatif nitrate au Gosfilmofond et est donc interdite au visionnage pour des raisons techniques, le document d'archive que nous avons traduit est pour le moment la seule source qui permette de reconstituer le film trophée Le Tibet. L'étude du film uniquement à travers des sources écrites oblige le chercheur à rester prudent : la pellicule peut s'avérer finalement différente du projet écrit que nous avons consulté. Néanmoins, ce document peut être considéré comme un témoignage et une source importants dans la perspective plus large d'une histoire du cinéma soviétique de propagande.

\section{Renvois bibliographiques}

Albera François, « Cinéma soviétique des années 1924-1928 : le film de montage/document, matériau, point de vue », in Jean-Pierre Bertin-Maghit (dir.), Une histoire mondiale des cinémas de propagande, Paris : Nouveau monde éditions, 2008, pp. 83-91.

Andreyev Alexandre, Soviet Russia and Tibet : the Debacle of Secret Diplomacy, 1918-1930s, Boston : Brill, 2003.

Gurčenko Ljudmila, Applodismenty, Moscou : Centrpoligraf, 2000.

Kenez Peter, Cinéma and Soviet Society, 1917-1953, New York : Cambridge University Press, 1992.

Letopis' rossijskogo kino. 1946-1965, Moscou : Kanon+, 2010.

Pozner Valérie, « «Joué» versus «non-joué». La notion de «fait» dans les débats cinématographiques des années 1920 en URSS », Communications, 2006, n79, « Des faits et des gestes. Le parti pris du document, $2 »$ [Numéro dirigé par Jean-François Chevrier et Philippe Roussin], pp. 91-104.

Pozner Valérie, « Le sort des films trophées saisis par les Soviétiques au cours de la Seconde Guerre mondiale », in Alexandre Sumpf et Vincent Laniol (dir.), Denis Rolland (collab.), Saisies, spoliations et restitutions : archives et bibliothèques au XX $X^{\mathrm{e}}$ siècle, Rennes : Presses universitaires de Rennes, 2012, pp. 84-95.

Taylor Richard, Film Propaganda : Soviet Russia and Nazi Germany, London - New York : Croom Helm - Barnes \& Noble, 1979.

Tsyvian Iouri, « Sagesse et perversion. Le remontage et la culture cinématographique soviétique des années $1920 »$, Cinéma, 2004, n 7, pp. 122-145.

Turovskaja Maja, « Kinoprocess : 1917-1985 », Kinovedčeskie zapiski, 2010, n 94/95, pp. 70-89. 


\section{Juliette Denis et Irina Tcherneva}

CERCEC - EHESS, Paris

\section{Épopée et avatars du film Brouillard rouge : circulation et réappropriation d'images de propagande (Lettonie soviétique, Europe sous domination nazie, États-Unis de guerre froide $)^{1}$}

Parmi les films de propagande nazie, une production issue de Lettonie occupée connaît une élaboration et une destinée particulières : Brouillard rouge (Sarkanā migla)². Le titre est extrait d'un poème pastoral letton de 1939, cité à l'ouverture du film. En 1942, dans le contexte de l'occupation nazie, il symbolise désormais l'annexion de la Lettonie à l'URSS en 1939-1940. Le « brouillard rouge » évoque l'obscurité communiste qui se serait abattue sur la Lettonie lors de son rattachement à l'URSS à l'été 1940, et qui aurait été dissipée par l'invasion de la Wehrmacht en juin 1941.

Comme bien des opus de propagande nazie, cinématographiques ou non, le film mobilise tous les ressorts de la haine des bolcheviks et des Juifs (Kallis 2005 ; Parret 1994 ; Vande Winkel 2008). Une institution cinématographique allemande, la Compagnie centrale des films de l'Est (Zentralfilmgesellschaft Ost m.b.H, plus loin - ZFO), et sa filiale de Riga, la Compagnie des films de l'Ostland (OstlandFilmgesellschaft m.b.H, plus loin - Ostlandfilm), ont pris l'initiative de cette production (Schlegel 2009 : 65-66). Les occupants délèguent la réalisation du film à un personnel recruté sur place. Les cinéastes locaux embrassent les principes de

1 Article réalisé dans le cadre de l'ANR « Le cinéma en Union soviétique et la guerre, 1939-1949», Atelier de recherches sur l'intermédialité et les arts du spectacle, ARIASCNRS (UMR 7172).

2 Sarkanā migla (Ostland film, réalisation Dmitri Tumilis, 1942, 19 min $06 \mathrm{sec}$ ), LVKFFDA (Archives audiovisuelles de Lettonie), $\mathrm{n}^{\circ} 1346$. 
la propagande nazie. Sans s'étendre sur le pacte germano-soviétique, pourtant à l'origine de la partition de l'Europe de l'Est entre l'Allemagne et l'URSS, le film dénonce l'« année terrible » vécue par la Lettonie en 1940-1941 (Šneidere 2005 : 33). La soviétisation de la Lettonie est présentée au prisme du changement de pouvoir, des exécutions d'opposants et de la déportation en Sibérie. Les concepteurs de Brouillard rouge détournent des images soviétiques issues d'un film tourné l'année précédente. Ils ajoutent des plans effectués ultérieurement pour étayer leur propos simplificateur et généralement fallacieux. À travers le montage et le commentaire, ils « judéisent » le régime stalinien et sa police, le NKVD. Le résultat satisfait les commanditaires. La ZFO envisage alors de diffuser le film dans les " territoires de l'Est », c'est-àdire la vaste zone soviétique sous domination allemande. Berlin supervise même une vingtaine d'adaptations destinées à toute l'Europe, occupée ou non. Plusieurs versions seront effectivement réalisées ${ }^{3}$. Cette ambition élève le film au rang d'étendard de la lutte contre la « barbarie judéo-bolchevique », dont la Lettonie serait une victime emblématique.

L'histoire de Brouillard rouge ne s'arrête pas avec la libération de l'Europe du fléau nazi. En 1954, le court-métrage réalisé aux États-Unis, My Latvia, réutilise ses images ${ }^{4}$. Cette réédition est le fruit du travail commun entre une agence américaine de propagande de guerre froide - l'United States Information Agency, plus loin, USIA - et un cinéaste letton en exil, Alberts Jekste. Ce dernier produit la commande américaine dénonçant les « crimes soviétiques en Lettonie » à partir du matériel compilé sous l'égide d'Ostlandfilm pendant l'occupation nazie. L'USIA s'engage dans une vaste campagne de traduction et de diffusion (Cull $2008: 109$; L'Hommedieu $2011: 276$ ). L'histoire de la Lettonie soviétique se retrouve une fois de plus sous les feux des projecteurs, cette fois-ci comme symbole de l'expansion et de la violence de l'URSS.

Les multiples versions et adaptations de Brouillard rouge constituent un cas de transfert, de migration et de détournement d'images particulièrement saisissant. Des

Les versions suivantes ont été consultées : Version allemande : Roter Nebel (réalisation : Voldemars Pūce, Ostlandfilm, Riga/Riga-Film, production : Janis Sīlis, août 1942, 1000-1200 m, 35 mm. Bundesarchiv n A-2570 ; version estonienne : Punane udu (1943, 7 min $49 \mathrm{sec}$ ), Rahvusarhiivi filmiarhiiv (Archives filmiques d'Estonie) $\mathrm{n}^{\circ} 2698$ (contrairement à la Lituanie et à la Lettonie, la version estonienne n'a pas été terminée ni diffusée) ; version lituanienne : Raudonoji migla (1944, 30 min 49 sec), LCVA, Kino documentu skyriaus vedejas (Archives cinématographiques et photographiques de Lituanie) $n^{\circ}$ 2427/35 ; version suédoise : Den Röda Dimman (Ostlandfilm, réalisation : Voldemar Pūce, image : Alberts Jekste, Eduard Kraucs, 1944, 417 m, 35 $\mathrm{mm})$, Bundesarchiv ; version française : Pluie de sang (1944, $495 \mathrm{~m}, 35 \mathrm{~mm})$, Archives du CNC ; version autrichienne : Der Rote Nebel (Ostlandfilm, Riga-Film, production : Janis Sīlis, 36-44 $\mathrm{min}, 35 \mathrm{~mm}$ ).

$4 \quad$ My Latvia (United States Information Agency, réalisation : Alberts Jekste, 1954, 35 $\mathrm{mm})$. Conservé à LVKFFDA n ${ }^{\circ} 4554$. 
images tournées en Lettonie soviétique en 1940-41, puis détournées et agrémentées de nouveaux plans par les Nazis et leurs collaborateurs en 1942, sont diffusées dans l'Europe en guerre, avant d'être transférées aux États-Unis dans la sortie de guerre, puis de nouveau utilisées pendant la Guerre froide. Cette compilation d'images incessamment réagencées constitue le fondement d'un discours antisoviétique nazi puis américain. La singularité du film n'est pas passée inaperçue. Ralf Forster par exemple, dans son article sur la ZFO, consacre plusieurs passages à ce film, et d'autres chercheurs le citent fréquemment (Forster 2011 ; Crips 2013). Cependant, le film et ses avatars n'ont jamais fait l'objet d'étude détaillée, et sa réutilisation aux États-Unis est peu connue. À travers l'étude des moutures du film et de sources écrites (soviétiques, nazies et américaines ${ }^{5}$ ), notre contribution se propose de retracer l'histoire de cet objet cinématographique. Notre analyse s'inspire d'une riche historiographie consacrée à la circulation et à la manipulation des images. La diversité des séquences et de leurs usages suppose de se pencher sur les réappropriations des images de l'ennemi, sur la représentation particulièrement crue d'atrocités, sur les discours véhiculés par le montage et le commentaire (Veray 1999 ; Horne \& Kramer 2005). Comment, d'un territoire à l'autre, d'un contexte politique à l'autre, ces images précises sont-elles choisies, tournées, montées, diffusées, transformées ? Nous nous pencherons d'abord sur l'élaboration et la diffusion de Brouillard rouge, puis de My Latvia. Notre dernière partie propose une étude longitudinale des séquences consacrées aux " atrocités », afin de cerner les remaniements successifs des images et les représentations que véhiculent les différents montages.

\section{Sarkanā migla : un projet européen de propagande nazie délégué aux cinéastes locaux}

La ZFO, créée en novembre 1941, se destine à la production et à la diffusion de la propagande cinématographique nazie en URSS occupée. Sa direction se subdivise en deux branches : l'une chapeaute le Reichskommissariat de l'Ukraine, et l'autre celui de l'Ostland, qui regroupe les trois républiques baltes et la Biélorussie. Cette deuxième filiale siège à Riga. La ZFO dirige la production de films de fiction, la diffusion de films allemands, et la réalisation d'actualités et de « documentaires $»^{6}$. Les occupants initient les commandes de films et valident les résultats (Forster 2011 :

$5 \quad$ Nous utilisons des archives provenant des centres de conservations suivants : Archives d'État de Lettonie (LVA), Archives d'État de l'histoire de la Lettonie (LVVA), Archives spéciales de la Lituanie (LYA), Archives d'État de l'art et de la littérature de Russie (RGALI), Archives nationales des États-Unis (NARA).

6 Au sujet de la situation du cinéma comme outil de propagande nazie en Lettonie, cf. Bundesarchiv (Freiburg, Abt. Militärarchiv), Archives de la Wehrmacht, RH 22/272. 
318-321 ; Schlegel 2009 : 65-66 ; Titarenko 2017). Le tournage et le montage sont assurés par les occupés, sous la double supervision de l'administration filmique et des autorités militaires. Cette délégation est étroitement limitée et contrôlée : à aucun moment la ZFO ne prétend laisser une quelconque autonomie aux occupés dans le domaine culturel. L'histoire de la création de Brouillard rouge le confirme. Le film est commandé par le chef du département de la propagande allemande du Reichskommissariat de Lettonie et sa réalisation est supervisée par le département ainsi que par les forces SS et $\mathrm{SD}^{7}$. Pourtant, à Riga, la ZFO Ostlandfilm concède à son personnel local une relative autonomie. En attestent les interrogatoires de plusieurs professionnels impliqués dans la réalisation de l'original letton et de la version lituanienne, ainsi que les documents saisis par l'administration soviétique après la guerre ${ }^{8}$. Certes, les structures berlinoises et les autorités d'occupation conservent la mainmise sur les projets initiaux et leur diffusion finale. La conception raciste des peuples soviétiques conduit à nier leur capacité intellectuelle et créative. Il n'empêche : les élites et les administrateurs locaux bénéficient d'une marge de manœuvre inconcevable dans le reste de l'URSS occupée.

Ce favoritisme s'explique par plusieurs raisons. Avant même l'opération Barbarossa, les Nazis distinguent les Lettons, les Estoniens - et dans une moindre mesure les Lituaniens - des autres peuples de l'URSS, destinés à l'anéantissement ou à l'assujettissement. Les peuples baltes ne sont pas des Slaves, et même si leur coexistence séculaire avec les Russes a souillé la pureté de leur sang, ils ne méritent pas le même sort que les habitants d'Ukraine ou de Biélorussie. Alfred Rosenberg, théoricien de la hiérarchie raciale et Commissaire du Reich de l'Ostland, prêche pour un traitement différencié des peuples conquis. Il prône la création de gouvernements soumis, mais autonomes dans les territoires baltes, une fois débarrassés de la population juive et de l'influence russe. Hitler et Himmler, dubitatifs au départ, lui donneront finalement raison (Dallin 1970 : 49). Rosenberg a de sérieux motifs de considérer l'espace balte avec une certaine bienveillance. Lui-même est né à Tallinn et a fait ses études à Riga. Il appartient à cette minorité des «Allemands de la Baltique», lointains descendants des chevaliers teutoniques qui ont colonisé la région au XIII ${ }^{\mathrm{e}}$ siècle. Cette communauté, longtemps maître politique et économique des régions baltes, a connu plusieurs phases de "retour » vers l'Allemagne : après la Première Guerre mondiale (dont Rosenberg) et à la veille de l'annexion de l'Estonie et de la Lettonie par l'URSS, en 1939-1940. En ce qui concerne la Lettonie, ce "rapatriement »

LVA, f. 1986, op. 2, d. R-6272, 11. 16-20, 68.

8

Dossier de Steponas Uzdonas, LYA, f. K-1, op. 58, d. P1967. Nous tenons à remercier Lina Kaminskaitè Jančorienè de nous avoir donné accès à ce dossier. 
orchestré par le Troisième Reich concerne environ 65000 personnes 9 . À partir de juin 1941, les autorités militaires et civiles allemandes n'hésitent pas à employer ces fins connaisseurs du terrain balte dans les structures d'occupation. Les germano-baltes qui reviennent en Lettonie réactivent leurs réseaux avec l'élite lettone, elle-même souvent germanophone et russophobe (Ehrenbourg \& Grossman 1995 : 725-745 ; Lumans, 1993 ; Kurzem 2008 : 112). Un dernier élément incite les Allemands à percevoir le groupe ethnique letton avec une certaine indulgence : le déroulement même de l'invasion en juin 1941. Les Allemands exploitent dès leur arrivée le sentiment de soulagement, voire de sympathie qu'ils inspirent à une large partie des Lettons - du moins dans les premiers temps de l'occupation. Une année après l'annexion à l'URSS, une semaine après la déportation de 15000 personnes vers les camps de travail et les kolkhozes sibériens, bien des habitants de Lettonie perçoivent l'arrivée des Allemands comme une libération. Cette situation autorise une mise en place rapide et efficace des politiques d'occupation, avec l'appui des locaux (Statiev 2010 : 53-96 ; Ezergailis 1996 : 127-135). Dès l'été 1941, la chasse aux rares communistes clandestins et partisans s'enclenche, l'abolition de la réforme agraire exclut les paysans pauvres des terres que le pouvoir soviétique leur avait concédées, et surtout, le massacre des Juifs de Lettonie démarre immédiatement (Ezergailis 1996). Même s'ils n'officialisent aucune forme d'autonomie, les occupants confèrent la plupart du temps au groupe national « letton» (ou « estonien », ou « lituanien ») certaines responsabilités, de plus en plus étendues au fur et à mesure que la guerre s'intensifie. Cette tendance globale en Lettonie se retrouve dans le milieu du cinéma (Forster 2011 : 322). Les autorités d'occupation nazies s'appuient sur un noyau de professionnels locaux et les petites structures cinématographiques préexistantes : en l'occurrence, le studio d'actualités et le studio de fiction de Riga (Tcherneva 2014 : 232-235).

On retrouve dans l'équipe de Brouillard rouge presque tous les professionnels lettons intégrés à la ZFO ainsi que des techniciens du studio des actualités. Ces figures locales ont commencé leur carrière lors des années d'indépendance de la Lettonie dans les années 1920 et 1930, et l'ont poursuivie sous le régime soviétique en 1940-1941, puis sous l'occupation nazie. Le personnel cinématographique n'est guère affecté par les différents changements de régimes (Tcherneva \& Denis 2017). L'interlocuteur principal des commanditaires allemands du film est Voldemars Pūce (Tcherneva 2014 : 236-242). Le cinéaste autodidacte, de formation théâtrale, s'est affirmé comme réalisateur de fiction avec son premier long métrage Kaugurieši ( $L a$ Révolte des Kaougours, studio de Riga ${ }^{10}$ ). Pendant l'occupation nazie, il est promu

9 Jean de Beausse, Carnets, 1939-1940, manuscrit non publié conservé à l'Ambassade de France en Lettonie, entrée du samedi 07.10.1939. 
au poste de directeur du studio Rigas-Film, puis dès la fin de 1943 il devient le directeur de Ostlandfilm. Il porte la responsabilité de l'ensemble de la production cinématographique du studio ${ }^{11}$. Le réalisateur du film, Konstantin Tumils-Tumilovičs, vient du milieu littéraire et théâtral ${ }^{12}$. Parmi les opérateurs, il convient de mentionner Eduards Kraucs, directeur du studio des actualités de Lettonie indépendante et propriétaire de salles de cinéma à Riga. En 1940 et 1941, les autorités soviétiques, après avoir réquisitionné son cinéma le Palace, l'emploient comme opérateur en Lettonie ${ }^{13}$. Son parcours d'avant-guerre se rapproche de celui du producteur du film, Jānis Sīlis, opérateur de formation. Quant à Alberts Jekste, l'un des opérateurs présumés d'une des versions de Brouillard rouge, et futur promoteur du film aux États-Unis, il a occupé divers postes de technicien à la radio et dans le cinéma. Les Soviétiques lui confient en 1940 la direction du studio de films de fiction de Riga. Fin juin 1941, alors que la Wehrmacht s'approche de Riga, il cache, avec d'autres employés, le matériel du studio afin de le soustraire à l'évacuation vers l'Est. Dans la nuit du 30 juin au $1^{\text {er }}$ juillet, il quitte son poste de directeur des studios pour la Radio nationale ${ }^{14}$. Le lendemain matin, Jekste, avec l'aide de Pūce, annonce la « libération » de Riga, invite les auditeurs à hisser les drapeaux lettons, et diffuse l'hymne national letton. Il appelle aussi à prendre les armes contre les communistes locaux et la population juive. Les Allemands se rendent rapidement maitres des ondes, mais lui laissent la direction de la radio jusqu'en octobre 1941. Malgré cette soumission aux occupants, il est arrêté et emprisonné au camp de Salaspils, près de Riga, entre 1942 et 1943 (Niedra 1999 : $449)^{15}$. Nous n'avons jusqu'ici pas encore déterminé le motif de son incarcération ni celui de sa libération. À partir de 1943, il filme les batailles opposant les « volontaires lettons » des légions de la Waffen SS à l'Armée rouge. Tout comme ses collègues, il navigue entre diverses spécialisations artistiques et techniques, avant et pendant l'occupation nazie.

Ostlandfilm confie donc ses productions, et notamment Brouillard rouge, à ce personnel restreint, en voie de professionnalisation. Durant l'occupation allemande, les cinéastes lettons (tout comme leurs homologues en Ukraine) réalisent surtout des

LVA, f. 1986, op. 2, d. 8320, t. 1, 11. 242-249.

12 Dossier de Steponas Uzdonas (un des créateurs de la version lituanienne du film), LYA, f. K-1, op. 58, d. P1967. Dossier de Voldemars Pūce, LVA, f. 1986, op. 2, d. P-8320, t. 1.

13 Hoover Institution Archives, Eduards Kraucs' Papers, box 1.

14 Dossier de Voldemars Pūce, LVA, f. 1986, op. 2, d. P-8320, tt. 1 et 2.

15 En outre, de rares informations que nous avons trouvées sur ce personnage proviennent d'un site letton (Document en ligne consulté le 13.04.2017, https://nekropole.info/ lv/Alberts-Jekste) dont les données non référencées doivent être considérées avec précaution. 
courts métrages adressant des messages antibolcheviques, antisémites et nationalistes, ou insistant sur la contribution des travailleurs et des « volontaires de la légion SS » lettons dans l'effort de guerre contre l'URSS. Brouillard rouge occupe une place à part dans la production d'Ostlandfilm, en raison de sa durée, et de l'ambitieux projet de diffusion dont il fait l'objet. Qualifié de « reportage antibolchevique de style documentaire » dans la terminologie officielle de la ZFO (Forster $2011: 323$ ), le film retrace d'abord la prise de pouvoir par les Soviétiques, puis les « atrocités judéobolcheviques ", les destructions occasionnées par la retraite de l'Armée rouge, et enfin la « libération » du pays par la Wehrmacht acclamée par la foule. L'objectif nazi entre en adéquation avec les préoccupations des concepteurs lettons, à savoir la dénonciation de l'annexion à l'URSS en 1940. De cette collaboration naît le fil conducteur du film : les Juifs sont responsables de tous les maux subis par la Lettonie.

Pour étayer la doctrine antisémite, Sarkanā migla et ses versions ultérieures s'appuient sur une constellation d'images " migrantes", relues et réinterprétées à chaque nouvel assemblage. Plusieurs séquences sont reprises au documentaire soviétique de 1941, À la rencontre du soleil, qui glorifie le « rattachement volontaire de la Lettonie à $1^{\prime}$ URSS $»^{16}$. Le procédé très largement mis en œuvre dans le film nazi consiste en un renversement, voire un détournement pur et simple des images de l'ennemi soviétique. Entre ces images d'archives détournées, les réalisateurs intercalent d'autres plans hétéroclites : des séquences réalisées pendant l'invasion et l'occupation allemande, des extraits des actualités filmées Deutsche Wochenschau, des plans de films de propagande nazis de fiction ou de style documentaire. Brouillard rouge mêle ces images sans jamais en indiquer la provenance, pratique traditionnelle à cette période. Le discours antisémite naît du montage et il est soutenu par la voix off. Les séquences montrant l'ouverture de fosses communes portent l'intensité dramatique à son comble. Ce passage illustre, d'après le commentaire, l'exécution de prisonniers à Riga lors de la retraite soviétique de juin 1941, dont les cadavres auraient été découverts par les Allemands quelques mois plus tard. Comme nous le détaillerons par la suite, l'exhumation des fosses constitue le point d'orgue de la schématisation des « atrocités bolcheviques » suggérées par l'ensemble du film.

Pour la ZFO, Brouillard rouge incarne la lutte contre les ennemis judéobolcheviques, et mérite une diffusion européenne (Forster 2011 : 326). La ZFO compte sur l'intérêt du public européen, occupé ou non, pour toutes formes d'images d'« atrocités », qui ont depuis la Première Guerre mondiale accoutumé le spectateur à ce type de documents. Lorsque la Deuxième Guerre mondiale débute, les leaders nazis (comme les autres belligérants) ont à l'esprit les procédés mis en œuvre lors du

16 Archives d'État de la Fédération de Russie des documents photographiques et cinématographiques (Rossijskij Gosudarstvennyj Arhiv Kinofotodokumentov RGAKFD), Navstreču solncu (À la rencontre du soleil), 1941, nº 3826. 
précédent conflit mondial. Hitler lui-même s'est montré admiratif, dans Mein Kampf, de la capacité des Anglais à maintenir le moral de leurs troupes au front et de la population à l'arrière grâce à la Greuelpropaganda, ou la " propagande des atrocités " (Becker 2017). Les Nazis préconisent très tôt de généraliser cette pratique. Brouillard rouge s'inscrit dans cette tradition et cherche à toucher tous les peuples habitués à la « démonstration par les atrocités ». En Lettonie même, durant l'occupation, d'autres médias prennent en charge la dénonciation des « atrocités bolcheviques » (fig. 1). Des journaux nationalistes interdits par le pouvoir soviétique en 1940 renaissent dès l'été 1941. Ils publient des listes partielles de condamnés, ils narrent les épisodes de déportation stalinienne, en y infusant un antisémitisme radical et permanent ${ }^{17}$. Des pratiques similaires se retrouvent ailleurs en territoire occupé soviétique. La ZFO espère donc introduire en profondeur l'idéologie antibolchevique et antisémite grâce à un support déjà éprouvé, et largement répandu dans tous les médias des zones occupées.

Notre recherche rend compte d'une distribution internationale du film. Des traductions - ou plutôt des adaptations - lituanienne, suédoise, autrichienne, allemande et française sont finalisées et diffusées avec plus ou moins d'intensité en fonction des pays (Crips 2013 : 243-244). Cependant, la ZFO échoue à inonder toute l'Europe de ces images. Brouillard rouge, au même titre que d'autres productions de propagande, n'obtient pas le succès escompté. Plusieurs exemples l'attestent. Siegfried Kyser, directeur de la production à la ZFO, parcourt divers pays européens pour évaluer les possibilités de la diffusion de Brouillard rouge. Il rapporte que la distribution du Danemark l'a rejeté, avançant les sentiments antiallemands de la population. La distribution en Suisse se révèle également impossible, de même dans l'ensemble des pays neutres. Dans les villes soviétiques occupées, la direction de la ZFO note dès juillet 1943 que les " films anticommunistes suscitent un rejet clairement affirmé » (Forster 2011 : 327-328). En URSS occupée et ailleurs en Europe, les populations expriment à demi-mot leur méfiance envers les discours et les images portant sur les « atrocités ». L'Allemagne nazie déploie d'ailleurs des politiques diversifiées en fonction de contextes des pays occupés et neutres (Welch \& Vande Winkel 2011). Le « bourrage de crâne » de la Première Guerre mondiale et les excès de la propagande des débuts de l'occupation nazie ont-ils abaissé le seuil de tolérance des spectateurs et accentué leur analyse critique des images? Un constat d'échec explique sans doute que la version estonienne de Brouillard rouge, bien que prévue, n'ait jamais été achevée ni diffusée. Les films de propagande n'attirent pas vraiment les foules en temps de guerre, si bien que les autorités d'occupation optent pour la distribution de films divertissants et affichés a priori comme apolitiques (Titarenko 2017). De plus, Brouillard rouge est 
promu en 1943 et adapté en 1944. Ses copies deviennent opérationnelles au moment où la situation militaire devient menaçante pour l'Allemagne, et où le pouvoir stalinien gagne en popularité. Le Reich a alors perdu une grande partie des territoires occupés et il lutte contre la progression de l'Armée rouge. Depuis la bataille de Stalingrad en 1943, les spectateurs n'adhèrent plus à la haine inconditionnelle de l'URSS. Les projets de diffusion demeurent donc inaboutis. La disgrâce touche même l'ensemble de la structure : en 1944, le Ministère de la Propagande à Berlin conteste l'utilité de la ZFO, accusée de ne pas avoir su promouvoir des films en URSS occupée. Désormais superflue, la ZFO perd ses moyens institutionnels et financiers.

\section{My Latvia (1954), un film de Guerre froide. Migration des hommes, ajustement du message}

Bien qu'érigé en bannière de la dénonciation du judéo-bolchevisme, Brouillard rouge n'aura pas comblé les attentes de ses promoteurs. Mais la fin de la guerre et la Guerre froide inaugurent une nouvelle ère de reconnaissance du film. Face à sa crise interne, la ZFO suspend son activité à Riga (Forster 2011 : 328-329). Elle conserve cependant son personnel letton dont elle redéploie les tâches. Entre mars et octobre 1944, Pūce, Jekste, Kraucs, Tumils-Tumilovičs et d'autres membres du personnel du studio quittent la Lettonie pour l'Allemagne. Comme d'autres collaborateurs choyés par les forces d'occupation, ils bénéficient de conditions d'évacuation précoces et privilégiées (Kurzem 2008 : 222-225). Ils ont pu déménager la quasi-intégralité des installations et des bobines du studio de Riga vers l'Allemagne ${ }^{18}$. Toujours employés de la ZFO, ils caressent probablement l'espoir de continuer à travailler dans les structures de production filmique en Allemagne. En janvier 1945 encore, la compagnie plaide auprès de l'UFA pour que celle-ci embauche plusieurs professionnels lettons, sans succès. La plupart de ces cinéastes se retrouvent après la capitulation allemande dans les camps de Displaced persons (DPs) des zones américaine et britannique. Comme les 800000 DPs originaires d'Europe de l'Est (dont environ 130000 de Lettonie), les cinéastes tentent d'améliorer leur quotidien et d'accroître leurs chances d'émigrer, en s'attirant les faveurs des Occidentaux ${ }^{19}$. Dans la confusion de l'aprèsguerre, et dans la nouvelle donne de la Guerre froide, des collaborateurs notoires ne sont ni jugés, ni rapatriés en URSS, ni privés du droit à l'émigration (Denis 2013). Les agences américaines (dont la jeune CIA) ne sont pas défavorables au recrutement de DPs venus de l'Est, qui ont l'avantage de bien connaître les langues et le contexte

18 LVA, f. 1986, op. 2, d. P-8320, tt. 1 et 2 ; f. 1986, op. 1, d. 40444 ; f. 1986, op. 2, d. P-6272. Juliette Denis en avril 2010, Riga. 
soviétiques. Leur loyauté est également à toute épreuve. "Qu'importe qu'ils aient été pronazis, puisque leur anticommunisme ne fait aucun doute $\gg-$ telle est l'opinion décomplexée de bon nombre d'individus et d'institutions sous Truman (Genizi 1993 : 74-75). Cette bienveillance profite à plusieurs créateurs de Brouillard rouge. Kraucs réussit par exemple à intégrer les réseaux cinématographiques de l'UNRRA (United Nations Relief and Rehabilitation Administration), une organisation internationale venant en aide aux réfugiés. Kraucs réalise en Allemagne des films sous sa houlette. Il émigre ensuite aux États-Unis où il poursuit sa carrière ${ }^{20}$. D'autres partent pour le Canada ou l'Australie, deux pays dont les conditions d'admission des DPs sont encore plus souples que celles des États-Unis.

Le parcours des équipements et des bobines de film croise ces trajectoires (Sumpf \& Laniol 2012). Certains employés de la ZFO en apportent dans leurs affaires personnelles, mais le plus grand volume est envoyé à Burgau en Bavière en juin $1945^{21}$. Une partie de rushes a ainsi pu être récupérée par l'armée américaine. L'itinérance du matériau est corrélée à celle d'un homme et de son groupe : Alberts Jekste et les DPs lettons. Après sa libération du camp de Salaspils, Jekste, en tant que correspondant de guerre, suit les batailles des marais de Volhov et de Liepāja, et accompagne la retraite des légions lettones et de la Wehrmacht en Allemagne. Il franchit l'Elbe à pied pour rejoindre le secteur américain, où il retrouve sa famille. Lors de son séjour au camp de DPs à Blomberg, en secteur britannique, il renoue avec la production cinématographique, à l'instar de Kraucs (Niedra 1999 : 449). Il participe au documentaire Qui sommes-nous, que pouvons-nous faire (Kas mēs esam un ko mēs spējam) qui expose les innombrables vertus des DPs lettons, capables de s'intégrer dans n'importe quelle nation occidentale ${ }^{22}$. En automne 1950, le gouvernement de Terre-Neuve rencontre des DPs lettons et les invite à y déménager. Jekste fait partie du petit groupe qui s'y installe en $1952^{23}$.

Des rushes et des séquences de Brouillard Rouge parviennent ainsi outreAtlantique. Déjà en 1944, les Nazis et les collaborateurs lituaniens avaient songé à diffuser le film auprès des Alliés anglo-saxons : Brouillard rouge pouvait, d'après eux, contribuer au discrédit de l'URSS et à la désolidarisation de leurs ennemis ${ }^{24}$.

20 Hoover Institution archives, Eduard Kraucs' Papers, box 1.

21 LVA, f. 1986, op. 2, d. P-8320, t. 1, 11. 16-18.

22 Vilis Lapenieks 1947, Studio de Riga en Allemagne .

23 Document en ligne consulté le 13.04.2017, https://nekropole.info/lv/Alberts-Jekste. Voir note 15 .

24 En guise d'exemple, N. Derksnys, « Užfiksuota kruvina teisybė » [« Réalité sanglante saisie par le film »], Naujoji Lietuva [Nouvelle Lituanie - le principal journal de Vilnius 
C'est grâce aux trajectoires de l'après-guerre et aux mécanismes de guerre froide que des images se retrouvent finalement aux États-Unis. En 1953, Eisenhower, tout en prônant l'apaisement des relations avec l'URSS poststalinienne, cherche à intensifier la lutte idéologique et à populariser la " théorie des dominos » (selon laquelle un pays devenant communiste risque de faire basculer tous ses voisins). Il crée à cette fin l'United States Information Agency (USIA). L'agence vise à rapprocher les États-Unis de leurs alliés et à promouvoir le discours antisoviétique. Elle est dotée de moyens colossaux afin de concurrencer la propagande soviétique dans le monde. La quatrième section de l'USIA est spécifiquement dédiée à la production de films documentaires. Elle cherche à s'affranchir de la coopération d'Hollywood, suspectée en cette période d'antipatriotisme et de pro-communisme. Les films sont réalisés en interne (Cull 2008 : 109).

L'institution américaine centralisée rencontre les préoccupations des communautés baltes dispersées dans les pays du Bloc de l'Ouest. Après leur séjour provisoire en Allemagne, de nombreux réfugiés estoniens, lettons et lituaniens ont émigré aux États-Unis, au Canada, en Australie et poursuivent en exil leur travail de dénonciation de l'URSS. Les groupes baltes en immigration aspirent à sensibiliser les autorités politiques états-uniennes quant au statut de leurs pays d'origine. Dans les années 1950, des associations produisent et diffusent entre elles des productions filmiques qui attestent de crimes commis par les Soviétiques ${ }^{25}$. La convergence des objectifs de l'USIA et des activités politiques des immigrés baltes aboutit aux réemplois de Brouillard rouge dont My Latvia (1954). Nous n'avons pas encore identifié comment l'USIA en vint à récupérer les bobines et à employer Jekste. Une prochaine analyse des sources permettra sans doute de savoir si le réalisateur letton en exil s'est manifesté aux autorités américaines, ou si l'USIA a entamé une recherche systématique de personnel et de matériel. Quoi qu'il en soit, au moins six versions différentes de $M y$ Latvia sont montées et tirées et circulent entre les communautés baltes en émigration. Leur diffusion en interne est facilitée par le format du tirage du film en $16 \mathrm{~mm}^{26}$. L'agence traduit le film en 22 langues. L'USIA affirmait, à la fin de l'année 1953,

pendant l'occupation nazie], 23.03.1944, p. 4.

25 Citons en guise d'exemple, le court métrage Why we escaped (1951) réalisé en Amérique du Nord par la communauté d'émigrés lituaniens. En outre, en 1950, le journal The Tablet, International Catholic Review Weekly publie un texte intitulé « The Baltic Tragedy » et écrit par un Lituanien résidant aux États-Unis au sujet des déportations des Lituaniens par les occupants russes. Document en ligne consulté le 12.07.2016 $<$ http://archive.thetablet.co.uk/article/8th-july-1950/14/the-baltic-tragedy-dear-sirinyour-issue-of-june-2>.

Deux d'entre elles sont conservées à LVKFFDA. 
atteindre une audience annuelle de 500 millions de personnes et disposer de 6000 projecteurs (Cull 2009: 109).

My Latvia (1954) débute par un discours de Jekste, assis face caméra, qui se présente comme réalisateur et témoin. Il valide la véracité des images, ainsi que leur valeur démonstrative et pédagogique. Il achève sa présentation par une interpellation du spectateur : «D'autres pays connurent le même sort que la Lettonie. Cela pourraitil être le vôtre ? » Une introduction rapide présente la Lettonie indépendante à l'aide de quelques images issues des documentaires traditionnels des années 1930, qui présentent les traits culturels des peuples. Les Lettons y sont représentés comme un peuple rural paisible, attaché à sa culture et à ses coutumes. Le commentaire insiste sur des valeurs assimilables par un public américain : la lutte pour l'indépendance nationale, la piété protestante du peuple letton ( God bless Latvia, tel est notre hymne »), la quiétude sociale et l'homogénéité ethnique de la société lettone. Autant de vertus balayées par les « crimes communistes » exhibés dans la suite du film. Cette démonstration en deux temps s'inscrit dans la continuité directe des discours élaborés par la communauté lettone en exil après la guerre. Depuis 1945, les représentants des DPs lettons ont cherché à démontrer l'« assimilabilité » de leur groupe aux sociétés occidentales, notamment américaines L'ambassadeur de Lettonie à Washington, maintenu en poste par les États-Unis malgré l'annexion du pays à l'URSS, s'évertue à recueillir et compiler le matériel sur les crimes staliniens en Lettonie. Des listes de condamnés et de déportés, des descriptions d'arrestations ou d'expulsions lui sont transmises dès les années de guerre. Ces sources - qui lui parviennent le plus souvent grâce aux exilés - constituent le fondement de la démonstration de l'illégitimité de l'annexion à l'URSS et de la cruauté des nouveaux maîtres soviétiques (Denis 2013). My Latvia hérite donc autant des principes de propagande de guerre froide que de la construction discursive élaborée dans les rangs des exilés lettons depuis la fin de la guerre.

\section{Images d' " atrocités " : transformation du socle de Brouillard rouge à My Latvia}

Les images consacrées aux « atrocités » se retrouvent dans la constellation de productions visuelles que nous avons regroupées sous l'expression « Brouillard rouge et ses avatars ", c'est-à-dire dans les versions réalisées pendant l'occupation nazie et dans les adaptations élaborées aux États-Unis. Forgée à partir d'images disparates, cette séquence reste globalement inchangée dans toutes les versions du film, hormis quelques ajustements dans le montage et le commentaire. Nous donnons au terme d'« atrocités » une définition restreinte, conforme au discours porté par les films : il s'agit de mises à mort, d'images crues de cadavres, ou de plans suggérant la mortalité des « victimes du bolchevisme» lors des exécutions ou des déportations. Ces images 
fixes et animées s'ouvrent sur un réquisitoire global contre l'URSS : dans chaque version du film, les «atrocités » constituent le socle d'une dénonciation plus étendue, en accord avec les objectifs politiques du moment. L'analyse détaillée des plans et des commentaires permet de dégager les strates géologiques de cette argumentation, et les reprises successives des images de l'ennemi.

Si cette propagande a pu fonctionner, c'est que, même en tordant la réalité et en injectant un antisémitisme franc ou larvé, elle s'appuie sur une réalité historique indéniable : la soviétisation de la Lettonie a engendré des violences politiques. Il en va de même dans les autres territoires annexés en 1939-1940. En occupant les territoires annexés une à deux années après le rattachement à l'URSS, les occupants nazis, avec l'aide des collaborateurs, ont mis à jour les violences staliniennes. L'exemple le plus connu de crimes soviétiques « dévoilés » par les Nazis est l'assassinat des officiers de l'armée polonaise à Katyn. La propagande antisémite a également repris cet épisode (même si certaines victimes exécutées à Katyn étaient juives) (Marszolek 2011 : 51-52). Les phases de soviétisation de la Lettonie en 1940-1941 sont émaillées d'illégalités et de brutalités, sur lesquelles on ne peut faire l'impasse. L'annexion n'est ni reconnue d'un point de vue international, ni pacifique d'un point de vue intérieur (Alenius 2012 : 13-30). Le NKVD letton, sous la tutelle du NKVD moscovite, a entrepris des arrestations dès l'automne 1940. Ses cibles demeurent alors limitées. C'est avec la déportation du 14 juin 1941 que les victimes des condamnations et de l'exil forcé se multiplient : 15000 personnes sont reléguées dans les camps de travail et les villages sibériens (Viksne 2005 : 53-61). Fin juin 1941, débordé par l'avancée rapide de la Wehrmacht, le NKVD central décide de déplacer en urgence les prisonniers susceptibles de tomber aux mains des nazis (et donc de devenir des collaborateurs). Faute de temps, les prisonniers inamovibles sont exécutés. L'exhumation des cadavres - même si elle est chapeautée par les occupants nazis et les collaborateurs - n'en reflète pas moins un aspect de la brutalité de l'entrée en guerre de l'URSS (Manley 2009 : 45 ; Vladimircev \& Kokurin $2008: 68$ ).

Mais ce n'est pas tant l'analyse factuelle qui préoccupe les concepteurs du film en 1942 que la possibilité de transformer l'histoire récente en dénonciation unilatérale des bolcheviks et, surtout, des Juifs. Le détournement des images du film soviétique À la rencontre du soleil permet de judéiser les acteurs de l'annexion de la Lettonie. Le réemploi du film soviétique semble d'autant plus aisé que certains concepteurs lettons de Brouillard rouge avaient participé à sa réalisation. C'est notamment le cas de Kraucs, crédité dans le documentaire soviétique, et membre de l'équipe du film nazi : il s'est facilement approprié des séquences qu'il avait lui-même contribué à réaliser. Par exemple, la séquence de $A$ la rencontre du soleil montrant la foule en liesse acclamant le régime soviétique est réutilisée dans Brouillard rouge. Elle est accompagnée du commentaire suivant : «Les Juifs saluent les arrivants. Le peuple letton reste silencieux dans sa douleur ». La libération des prisonniers politiques avait 
également été mise en scène dans le film soviétique. En effet, la dictature nationaliste des années 1930 avait conduit à l'incarcération d'opposants politiques, notamment les membres du Parti communiste clandestin de Lettonie. Dans le film de 1942, ces prisonniers sont désormais qualifiés de droits communs et de Juifs. Entre les images d'archives, une succession de plans aléatoires sur des dossiers judiciaires individuels est censée apporter la preuve de l'identité de ces prisonniers : d'origine juive, ils auraient commis des crimes et seraient devenus les administrateurs locaux de la police et de la république soviétiques en Lettonie.

L'antisémitisme culmine dans la séquence des « atrocités ». Ces dernières portent sur le comportement des partisans soviétiques et du NKVD, sur les arrestations et la déportation, et enfin sur l'exécution de prisonniers. Deux témoignages filmés en studio par les réalisateurs de Brouillard rouge appuient la démonstration. Un policier letton (fig. 2) aurait été agressé par des « hooligans juifs [qui] ont attaqué la police avec des pierres ». Effectivement, les Aizsargi, les paramilitaires soutenant le régime dictatorial d'Ulmanis, ont été cantonnés dans leurs casernes par les manifestants prosoviétiques à l'été 1940. Mais leurs assaillants n'étaient pas plus juifs que lettons. Le second témoin est un jeune garçon, originaire de Latgale, soi-disant arrêté et torturé par les « tchékistes juifs » (fig. 3). Il expose les traces de tortures dont il aurait été victime. Le tournage de ces séquences vise à corroborer d'autres sources d'information par les témoins encore vivants. Il en va de même pour les documents écrits. Des documents « secrets » sont censés apporter preuve sur preuve de la déportation massive de la population, mais sont reproduits sans aucune rigueur (fig. 4). Par exemple, un texte administratif lituanien étaye les arrestations en Lettonie. Seul le souci de montrer une archive soviétique préside à ce choix, car rien ne permet d'affirmer que le texte de Lituanie traite de la répression. Les détournements de preuves sont tellement grossiers que même les membres du projet doutent de leur efficacité. Par exemple, plusieurs professionnels ayant participé à la fabrication du film témoignent entre 1945 et 1948 des discussions entre le réalisateur, le commanditaire et le directeur du studio filmique autour de l'« acceptabilité » du témoignage du jeune garçon de Latgale ${ }^{27}$.

Plusieurs images, fixes ou animées, illustrent la déportation des Lettons par les Soviétiques (fig. 5 et 6). L'initiative de la déportation du 14 juin 1941 est imputée aux décideurs juifs. « Les plans [sont] établis par les tchékistes juifs pour déporter des milliers et des milliers de Lettons, malades, enfants, dizaines de milliers de femmes et d'hommes ", commente la voix off. Les images sont tirées du film de fiction Le dernier Coup de marteau coréalisé par Alfred Stöger (Ufa) et Vilis Lapenieks (RigasFilm). Ce film parait au même moment que Brouillard rouge en automne 1942, en 
russe, ukrainien et finnois ${ }^{28}$. Faute d'images d'archives, inexistantes ou inaccessibles, les réalisateurs de Brouillard rouge reprennent ces images de fiction comme preuve tangible.

Brouillard rouge s'attarde longuement sur le sort des prisonniers incarcérés dans la prison de Riga et soi-disant fusillés massivement par le NKVD à la veille de l'invasion nazie (fig. 7 et 8). Pour ce faire, le montage articule des plans de la prison elle-même avec une séquence de l'exhumation de cadavres. Les prises de vue de la prison sont celles du documentaire soviétique $\dot{A}$ la rencontre du soleil : dans le film soviétique, elles attestaient de la cruauté du régime dictatorial letton. Désormais, elles symbolisent le système répressif soviétique. Le commentaire et l'échelle de plan accentuent la mise en scène des pièces et des objets de « torture ».

Ces images soviétiques sont suivies de tournages réalisés sous l'occupation nazie. Il s'agit de la découverte de fosses communes, en juillet 1941 à Baltezers et près de la prison centrale de Riga ${ }^{29}$. Rien n'atteste que les images de cadavres proviennent de cette époque ni de ce lieu. En effet, d'autres tournages de découverte des crimes soviétiques émaillent toute la durée de l'occupation. Filmées et photographiées ${ }^{30}$, accompagnées de parution d'articles, ces révélations sont instituées en moments forts de mobilisation locale ${ }^{31}$. Dans le film, la voix off ne donne ni la date ni les noms des victimes, mais souligne qu'il s'agit de Lettons ethniques - assassinés, bien sûr, par des Juifs vengeurs à la veille de la débâcle soviétique de juin 1941 :

Nous avons découvert les secrets de la cave de la Tchéka seulement plus tard. Dans la cour de la prison centrale, auprès du lac Baltezers, derrière cette clôture à Dreilini et dans bien d'autres endroits nous avons exhumé les corps des exécutés, enfants du peuple [ ]. Des centaines de patriotes lettons. Dans les poches des personnes torturées, on a trouvé des décisions de justice avec un contenu mensonger, toutes fabriquées sur le même modèle.

La clef de voûte de cette séquence tient à un enchaînement de plusieurs images fixes de cadavres, défigurés, filmés en gros plan. Les commentaires en off des différentes versions de Brouillard rouge leur assignent les identités de personnalités politiques et publiques changeantes en fonction du pays de diffusion. Une série de documents, là encore présentés comme les preuves écrites des condamnations (sans être, d'après nous, des archives pénales), insiste sur les coupables. Une flèche pointe les noms juifs des soi-disant « bourreaux ». La voix off poursuit : « derrière

28 Des letzte Hammerschlag. Universum-Film AG (Ufa), Berlin, ZFO et Rigas-Film, production : Otto Nay, 52-62 min, 1429-1700 m, $35 \mathrm{~mm}$.

LVA, f. 1986, op. 2, d. P-8320, t. 1, 1. 1-4.

30 LVA, f. 1986, op. 2, d. P-8320, t. 1, 11. 16 et ss.

31 Entretien avec Abrams Kleckins, mené par Irina Tcherneva à Riga, 12 avril 2010. 
ce document tragique on peut voir la gueule du judaïsme international ». Le portrait racial qui accompagne ces paroles (fig. 9) est également extrait du film Le Dernier Coup de Marteau, et ressemble à la couverture de l'album photographique Soushommes (Zemcilvēks en letton, 1942) (fig. 10).

Brouillard rouge est en effet étroitement connecté à la nébuleuse de propagande orale, écrite et audiovisuelle développée pendant l'occupation pour soutenir la politique nazie ${ }^{32}$. Il partage avec l'album Sous-hommes les mêmes procédés d'élaboration, et le même schéma de rhétorique visuelle. L'album a été fabriqué selon des méthodes relativement similaires à celles utilisées plus tard dans Brouillard rouge. Des photographes de la SS ont pris, localement, des prises de vue. Compilées dans des albums « nationaux », adaptations de l'album original Der Untermensch (1942), ces images sont reprises pour chaque zone d'occupation par des légendes qui en falsifient la provenance. Les Nazis ont largement distribué cette édition photographique en territoires occupés, allant jusqu'à en faire des expositions itinérantes. L'accent mis sur la dénonciation des meurtres commis par les « judéo-bolcheviks » (fig. 11-13 - y compris par le cadrage - préside sans doute aux choix de montage de Brouillard rouge.

Au sein du film, chaque étape de l'annexion et de la soviétisation, chaque « crime » suscite de soi-disant authentifications reposant sur des méthodes diverses (documents d'archives, prises de vues en mouvement, photographies, inscriptions, témoignages). La filiation de Brouillard rouge avec les opus d'autres supports de propagande en Lettonie est patente. Les réalisateurs lettons se sont approprié les techniques et les images des occupants, en les accordant à l'expérience soviétique en Lettonie. Cette convergence d'images est aussi un appui pour un discours antisémite à visée globalisante. L'histoire que les réalisateurs du film mettent en scène s'adapte facilement aux autres contextes nationaux. L'antisémitisme forcené est un liant politique, commun entre l'idéologie raciale nazie et les idées des nationalistes lettons. Les « atrocités » constituent l'unité de dénonciation des crimes juifs en URSS, quelle que soit la zone occupée. Le commentaire off finit même par se passer de la mention « bolchevique » tant la symbiose est totale. Il universalise l' « ennemi juif» et gomme progressivement la référence à l'URSS pour se concentrer sur ses « criminels juifs »,

32 Il est conçu et diffusé alors que sortent sur les écrans lettons d'autres films antisémites (Juif éternel), antibolcheviques et anti-slaves (Hitlerjunge Quex, Kolberg, La Ville dorée) (Parret 1994). de ce dernier avaient été massivement retirés de la distribution et des foyers dès l'installation du pouvoir politique soviétique. Entretien avec Ilya Lenski réalisé par Irina Tcherneva en mars 2013, Riga. 
favorisant la dénonciation de toute la population juive européenne, et la justification de son extermination.

Les « atrocités judéo-bolcheviques », séquence centrale de Brouillard rouge, sont reprises dans la réédition du film en 1954. My Latvia épure le film nazi des images (de fiction) et du discours explicitement antisémites, véhiculé notamment par la voix off. Les acteurs de la construction du régime soviétique et les « bourreaux » de la population lettone sont désormais qualifiés de « communistes lettons », de « Russes » ou de « criminels ». Cependant, la modification du commentaire et l'omission de certaines images ne suffisent pas à effacer totalement le propos antisémite. Certains plans demeurent extrêmement ambigus. Par exemple, les documents " prouvant» l'origine juive des criminels soviétiques sont récupérés tels quels : les noms à consonance juive y sont soulignés. La voix off se garde bien d'insister sur ce point, mais cette absence signale en elle-même l'antisémitisme du film initial, et révèle en creux l'origine nazie du film américain.

La séquence des assassinats et de leur découverte reste quasiment inchangée par rapport à Brouillard Rouge. En revanche, Jekste qui mène désormais le récit en personne y adjoint des éléments de contexte - quitte à les inventer. Il affirme avoir assisté à l'exhumation et à la cérémonie funéraire en juillet 1942. Le spectateur est prévenu de cette touche personnalisée, car Jekste s'exprime en son nom à l'ouverture de My Latvia (fig. 14 et 15). Il prédit de surcroît qu' " il serait certainement fusillé par les communistes » pour une telle dénonciation. Autre aspect significatif, il n'hésite pas à commenter les prises de vues sur un ton ému, accentuant l'horreur portée par les plans de cadavres. Si cette émotion privée est bien accueillie par les experts invités à visualiser le pré-montage du film, la phrase de montage des images qui date de la Seconde Guerre mondiale leur semble inappropriée. Ils appréhendent le scepticisme des futurs spectateurs face aux plans de cadavres anonymes ${ }^{34}$. On retrouve un dilemme identique à celui des années de guerre. Certes, le thème des atrocités est une arme éprouvée et efficace du discours politique, mais les spectateurs désabusés risquent de ne plus croire à cette forme classique, extrême et exagérée de propagande. Bien que la représentation des « atrocités communistes » ait été adoptée comme vecteur de propagande aux États-Unis depuis la guerre en Corée, les réticences à l'égard de ces images accompagnent donc le montage de My Latvia.

Si les images des cadavres exhumés demeurent le cœur du discours de My Latvia, le film s'attarde longuement sur d'autres forfaits soviétiques, moins crus et moins brutaux. Il dénonce les assauts russo-soviétiques sur le capitalisme et la culture nationale avec plus d'emphase et d'insistance que son précurseur nazi. S'y succèdent des épisodes

34 CD Jackson Log 6 August 1953 ; R. G. Johnson to Miss Jarolman on 20 December 1954, in File « La 891 Latvia General », RG 59, Box 8, Records of the Department of State, Baltic Lot File 1940-1961, NARA (Washington). 
sur la nationalisation, l'importation de la culture soviétique et la redistribution des terres. Dans l'opus américain, l'atteinte à la propriété privée devient un crime presque au même titre que la violence policière ou la perte de l'indépendance. Dans le contexte de 1954, la soviétisation économique, linguistique et culturelle apparaît comme une ingérence condamnable démontrant l'appétit mondial de l'URSS. Là où Brouillard rouge construisait un discours antibolchevique menant à une dénonciation antisémite unilatérale, My Latvia diversifie la révélation des horreurs du communisme.

Adhérant aux attentes des commanditaires, les cinéastes adaptent aux diverses exigences discursives l'histoire récente du pays. Brouillard Rouge ethnicise le système soviétique - et justifie ainsi un massacre d'une tout autre ampleur : l'extermination des Juifs. My Latvia, à son tour, s'interdit toute référence à son origine nazie et aux accusations antisémites, mais n'en reste pas moins tributaire de la reprise des images de ses adversaires politiques.

À douze ans d'intervalle, Nazis et Américains perçoivent la soviétisation de la Lettonie comme un élément idéal de leur dénonciation de l'URSS. L'élaboration et la médiatisation de Brouillard rouge puis de My Latvia sont servies par la conjonction de plusieurs circonstances favorables : la récupération du matériel cinématographique soviétique, la coopération des dirigeants nazis et des cinéastes lettons, la mise en scène des traces des exécutions du NKVD, l'exil des cinéastes et des images. Les images de l'ennemi sont relues à deux reprises : des plans soviétiques sont récupérés par les opérateurs œuvrant pour la propagande nazie, puis le montage nazi est retravaillé par les cinéastes de l'USIA. Entre hasard des trajectoires et des trouvailles, et promotions institutionnelles volontaristes, les films, d'une époque à l'autre, proposent un discours sur les « atrocités » soviétiques, imprégné de logiques propagandistes variées. Mais les relectures successives peinent à s'affranchir des logiques précédentes.

Les montages conservent les stigmates des versions antérieures, mais elles cherchent à les faire oublier. Au fil des migrations et des réappropriations, à force d'être redéfinies pour entrer en conformité avec les injonctions politiques, les images sont " infiltrées de fiction ", selon l'expression de Sylvie Lindeperg (Lindeperg 2012). Les concepteurs des films s'emploient à les authentifier par diverses méthodes fallacieuses, à les brasser dans un dispositif de dénonciation globale et orientée.

La déconstruction des versions de Brouillard rouge et de son remontage dans My Latvia met ainsi en lumière une succession d'impostures. La démarche que nous avons empruntée dans cet article semble d'autant plus nécessaire que, même aujourd'hui, une des moutures du film continue à circuler sans appareillage critique. Rééditée en 1985, et désormais disponible en DVD, une production de l'International Historic Film assume la responsabilité de montage et prétend avoir effectué des recherches supplémentaires. Le site postule la mise à disposition des historiens de nombreuses 
éditions des actualités filmées nazies ainsi que le film My Latvia, soi-disant montrés dans leur longueur initiale et sans commentaires négatifs ${ }^{35}$. Le replacement discursif d'un produit de plusieurs politiques propagandistes sur un terrain de légitimation scientifique coexiste avec une circulation libre du film sur internet et son usage par des mouvements politiques d'extrême-droite. L'interrogation sur l'origine des images et leur interprétation dans la voix off, l'analyse des contextes de production constituent dès lors autant de démarches indispensables à la réflexion sur ce type de « documentaires historiques ».

\section{Renvois bibliographiques}

Aleniuns Karl, «A Baltic Prelude to the Cold War : The United States and the Soviet Annexation of the Baltic States, 1939-1941 », in Olaf Mertelsmann, Kaarel Piirimäe (dir.), The Baltic Sea Region and the Cold War, Francfort : Peter Lang, 2012, pp. 13-30.

Becker Annette, Messagers de la tragédie. Sur Karski et Lemkin (titre provisoire), Paris : Fayard, 2017 (à paraître).

Crips Liliane, "Figures défigurées d'ennemis dans le cinéma nazi », in Françoise RicherRossi (dir.), L'autre et ses représentations au cinéma : Idéologies et discours, Paris : L'Harmattan, 2013, pp. 229-257.

Cull Nicholas John, The Cold War and the United States Information Agency: American Propaganda and Public Diplomacy, 1945-1989, Cambridge - New York : Cambridge University Press, 2008.

Dallin Alexander, La Russie sous la botte nazie [1957], Paris : Fayard, 1970.

Denis Juliette, «Complices de Hitler ou victimes de Staline ? Les déplacés baltes en Allemagne, de la sortie de guerre à la guerre froide », Le Mouvement social, 2013/3, n 244, pp. $81-98$

Ehrenbourg Ilya, Vassili Grossman (dir.), Le Livre noir sur l'extermination scélérate des Juifs par les envahisseurs fascistes allemands dans les régions provisoirement occupées de l'URSS et dans les camps d'extermination en Pologne pendant la guerre de 1941-1945 [1947], Paris : Actes Sud, 1995.

Ezergailis Andrew, The Holocaust in Latvia, 1941-1944: The Missing Center, Riga : The Historical Institute of Latvia, 1996.

Forster Ralf, " German Film Politics in the Occupied Eastern Territories, 1941-1945 », in David Welch et Roel Vande Winkel (dir.), Cinema and the Swastika, $2^{\mathrm{e}}$ éd., Basingstoke - New York : Palgrave Macmillan, 2011, pp. 318-343.

Genizi Haim, America's Fair Share. The Admission and Resettlement of Displaced Persons, 1945-1952, Detroit : Wayne State University Press, 1993.

Horne John, Alan Kramer, Les Atrocités allemandes, Paris : Tallandier, 2005.

Kallis Aristotle A., Nazi Propaganda and the Second World War, Basingstoke - New York : Palgrave Macmillan, 2005.

Kurzem Mark, La Mascotte [2007], Lausanne : Noir sur Blanc, 2008.

35 Document en ligne consulté le 22.09.2016<http://ihffilm.com/>. 
L'Hommedieu Jonathan H., Exiles and Constituents : Baltic Refugees and American Cold War Politics, 1948-1960 (thèse de doctorat), Turku : University of Turku, 2011.

Lindeperg Sylvie, La voie des images : quatre histoires de tournage au printemps-été 1944, Lagrasse : Verdier, 2012.

Lumans Valdis, Himmler's Auxiliaries: The Volksdeutsche Mittelstelle and the German National Minorities of Europe, 1933-1945, Chapel Hill (N.C.) - Londres : the University of North Carolina press, 1993.

Manley Rebecca, To the Tashkent Station. Evacuation and Survival in the Soviet Union at War, Ithaca - London : Cornell University Press, 2009.

Marszolek Inge, "Exploring NS-propaganda as Social Practice », in Olaf Mertelsmann, Central and Eastern European Media under Dictatorial Rule and in the Early Cold War, Frankfurt am Main : Peter Lang, 2011.

Niedra Mara, Teatris un kino : biografijas, Riga : Preses nams, 1999, vol. 1.

Parret Peter, «Kolberg (1945) comme film historique et un document historique », Historical Journal of Film, 1994, vol. 14, pp. 433-448.

Schlegel Hans-Joachim, " Ukraine-Filmgesellschaft MBH. NS-Filmpropaganda in der okkupierten Ukraine », in Johannes Roschlau (dir.), Träume in Trümmern. Film Produktion und Propaganda in Europa 1940-1950, München : Edition Text und Kritik, 2009, pp. 65-79.

Šneidere Irēne, "The First Soviet Occupation Period in Latvia, 1940-1941 », in Valters Nollendorfs, Erwin Oberländer (dir.), The Hidden and Forbidden History of Latvia under Soviet and Nazi Occupations 1940-1991, Riga : Institute of History of Latvia, 2005, pp. 33-42.

Sumpf Alexandre, Vincent Laniol (dir.), Saisies, spoliations et restitutions. Archives et bibliothèques au XXe siècle, Rennes : PUR, 2012.

Statiev Alexander, The Soviet Counterinsurgency in the Western Borderlands, Cambridge : Cambridge University Press, 2010.

Tcherneva Irina, Le cinéma de non-fiction en URSS : création, production et diffusion (19481968), thèse de doctorat, Paris : EHESS, 2014.

Tcherneva Irina, Juliette Denis, "Sovetizacija rižskih kinostudij, 1944-1949. Kadrovaja politika v zapadnoj territorii Sovetskogo Sojuza », in Valérie Pozner, Irina Tcherneva, Vanessa Voisin (dir.), Perežit'vojnu. Kinoindustrija v SSSR, 1939 - 1949 gody, Moscou : ROSSPEN, 2017 (à paraître).

Titarenko Dmitrij, « «Kak teper' pomnju na èkrane siluèt nemeckogo orla...» : kinematograf v žizni naselenija Ukrainy v period nacistskoj okkupacii (zona voennoj administracii) », in Valérie Pozner, Alexandre Sumpf, Irina Tcherneva (dir.), La propagande de guerre soviétique à l'écran, 1939-1949, numéro spécial de Conserveries mémorielles, 2017 (à paraître).

Vande Winkel Roel, « Le cinéma de propagande dans l'État nazi pendant la Seconde Guerre mondiale : un pouvoir limité », in Jean-Pierre Bertin-Maghit, Une histoire mondiale des cinémas de propagande, [Paris :] Nouveau Monde éditions, 2008, pp. 311-323.

Veray Laurent, « Les Faux qui font l'Histoire », Vingtième siècle, 1999, vol. 23, n 1, pp. 147150.

Viksne Rudite, "Soviet repressions against residents of Latvia in 1940-1941 : typical trends ", in Valters Nollendorfs, Erwin Oberländer (dir.), The Hidden and Forbidden History of Latvia under Soviet and Nazi Occupations 1940-1991, Riga : Institute of History of Latvia, 2005, pp. 53-61. 
Vladimircev N.I., Kokurin A.I., NKVD-MVD SSSR v bor'be s banditizmom $i$ vooružennym nacionalitičeskim podpol'em na Zapadnoj Ukraine, v Zapadnoj Belorussii i Pribaltike, Moscou : Ob"edinennaja redakcija MVD Rossii, 2008.

Welch David, Roel Vande Winkel (eds), Cinema and the Swastika, 2e éd., Basingstoke - New York : Palgrave Macmillan, 2011. 
Épopée et avatars du film Brouillard rouge ...

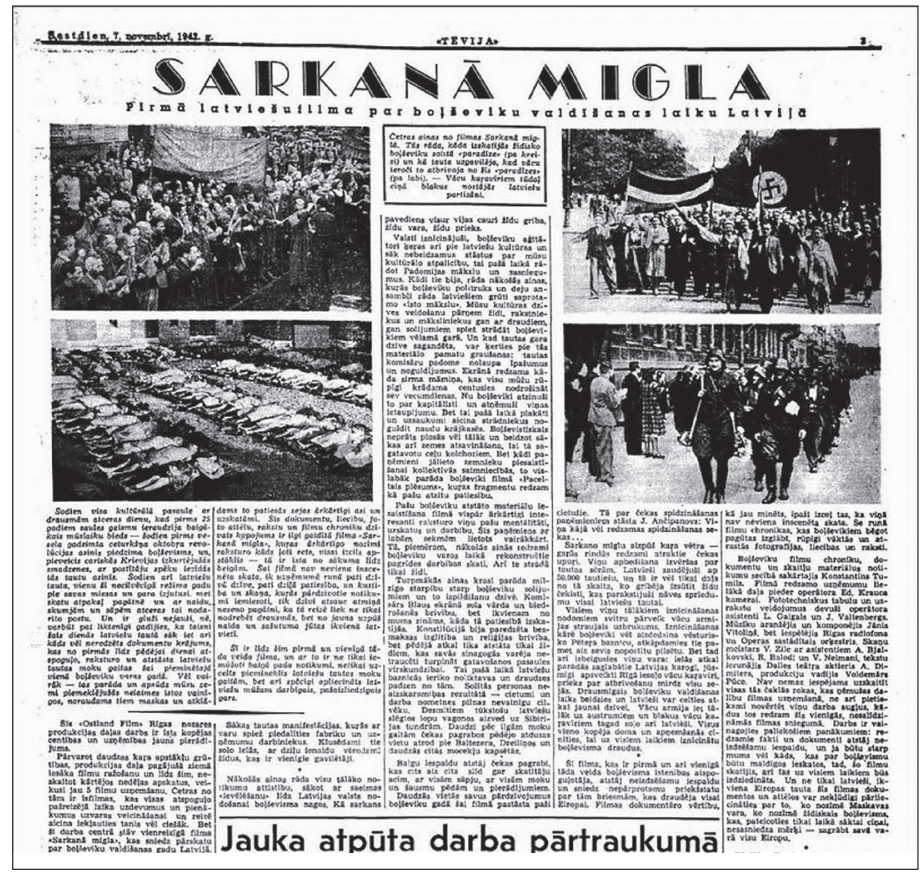

Fig. 1. Article sur « Sarkanā migla » [Brouillard rouge], Tēvija, 7.11.1942 (Bibliothèque nationale de Lettonie).

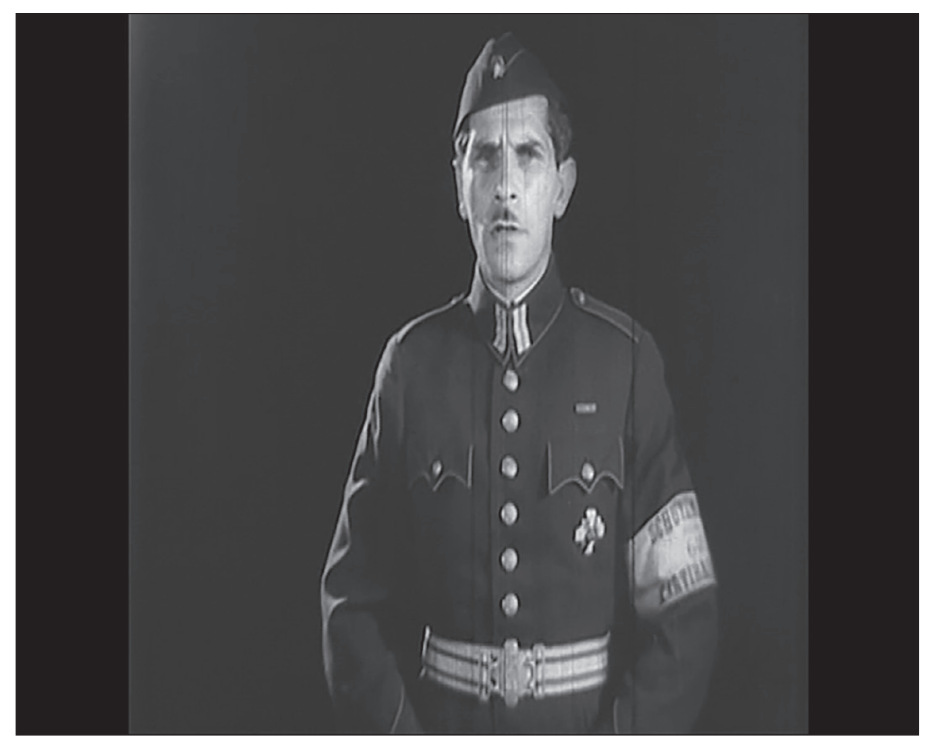

Fig. 2. Capture d'écran Brouillard rouge (1942). 


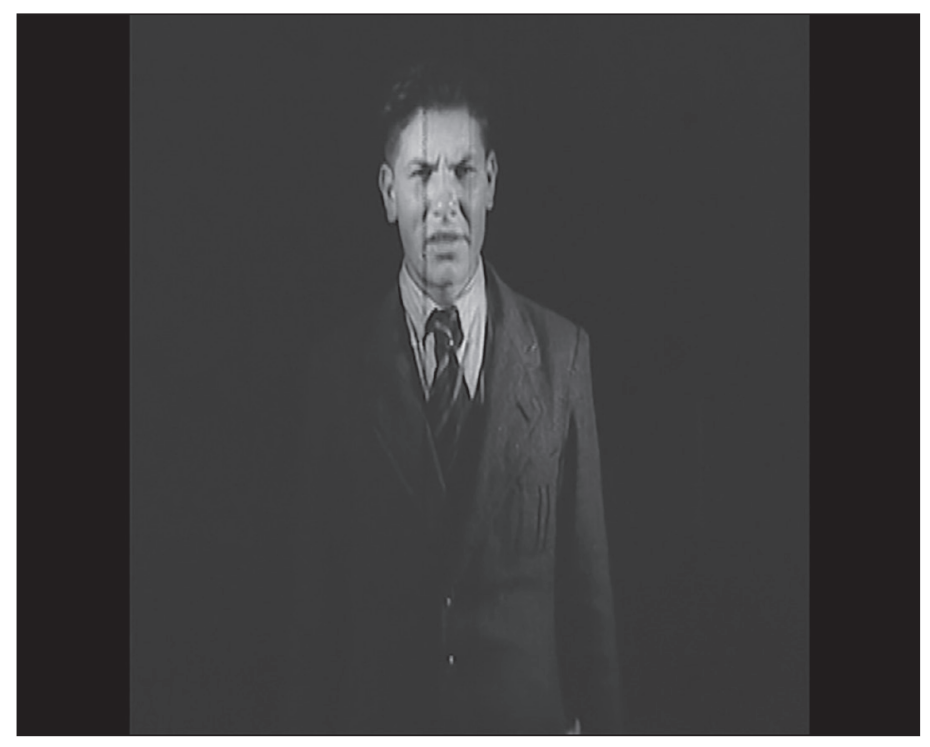

Fig. 3. Capture d'écran Brouillard rouge (1942).

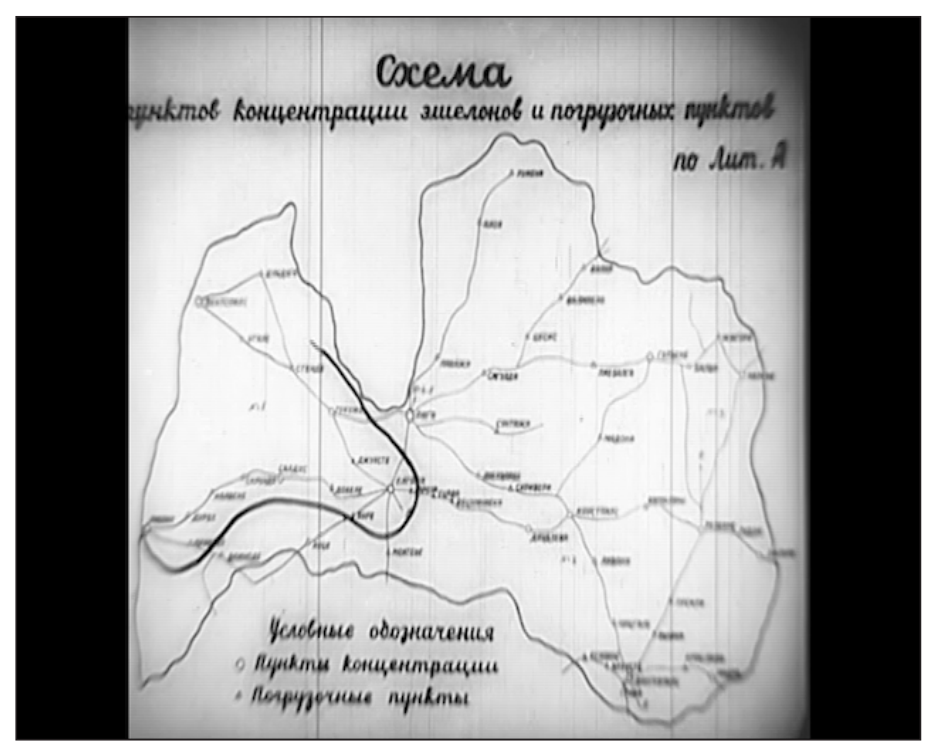

Fig. 4. Capture d'écran Brouillard rouge (1942). Document soviétique exposé. 
Épopée et avatars du film Brouillard rouge ...

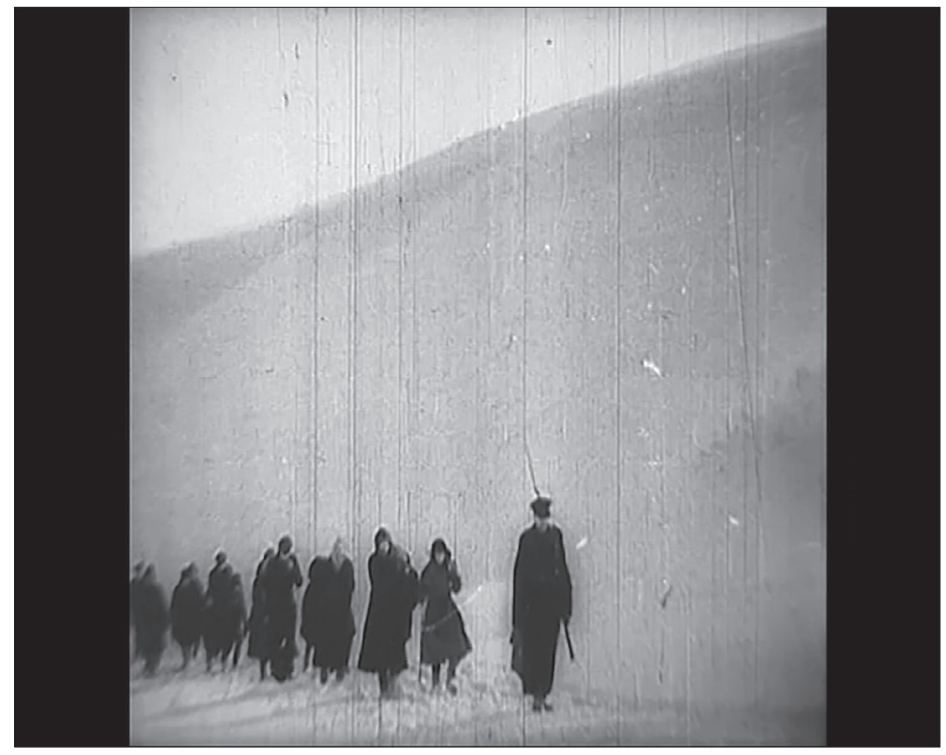

Fig. 5.

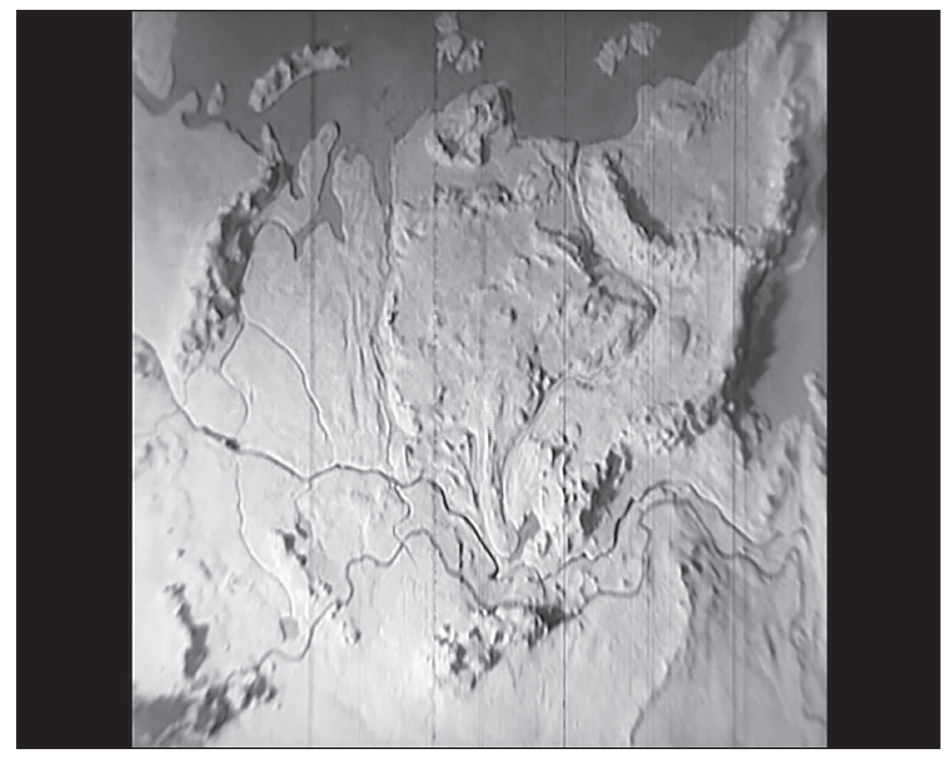

Fig. 5 et 6. Captures d'écran de Brouillard rouge (1942) : comment illustrer la déportation. 


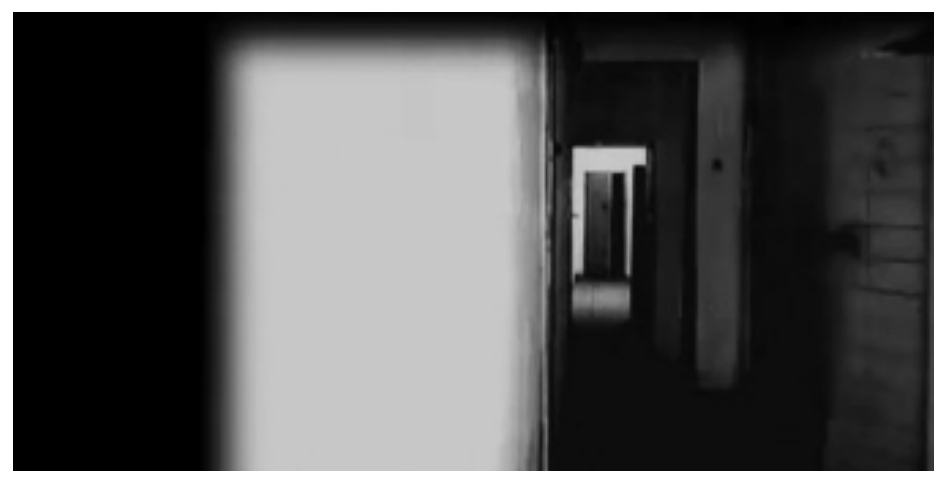

Fig. 7. Capture d'écran de Brouillard rouge (1942) : prise de vue de la prison.

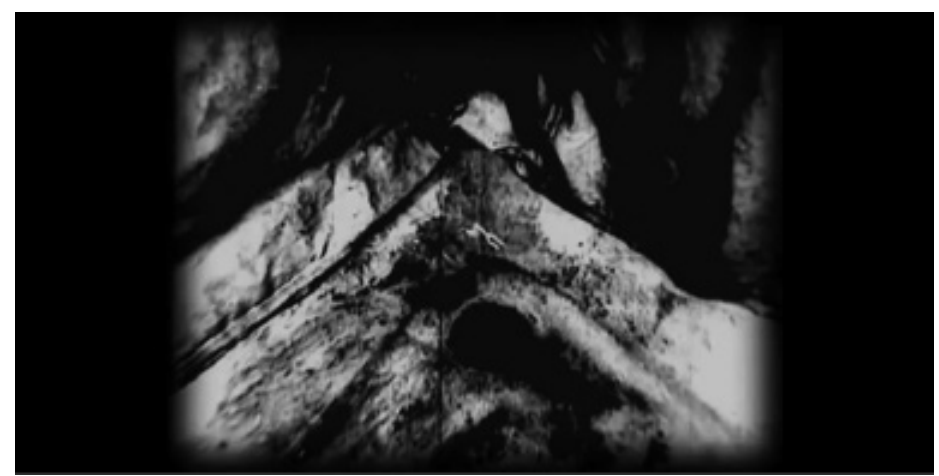

Fig. 8. Captures d'écran de Brouillard rouge (1942) : prise de vue de la prison.

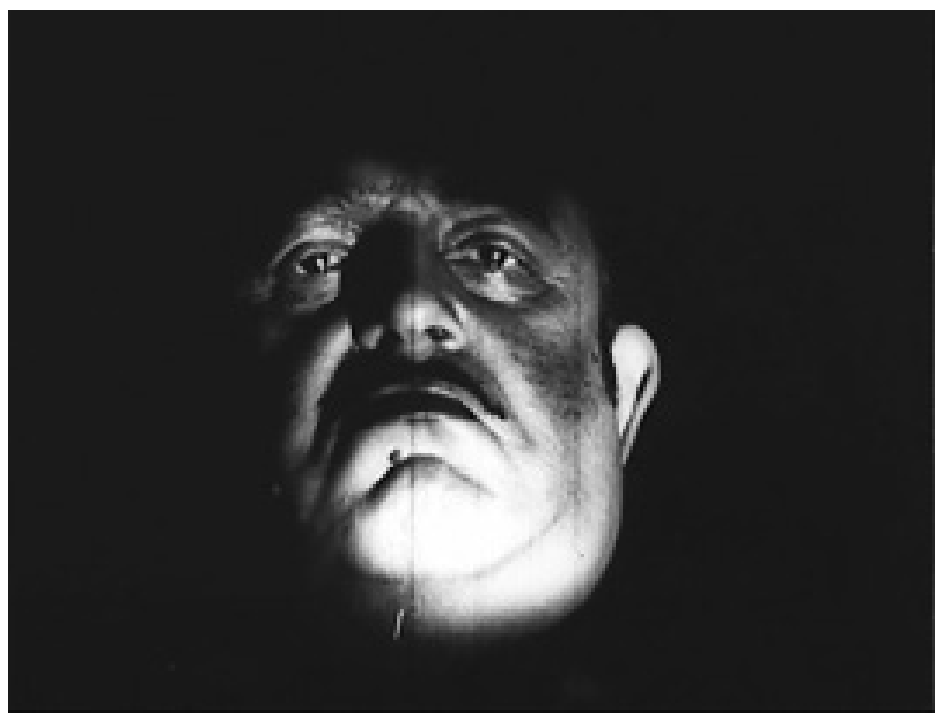

Fig. 9. Capture d'écran de Brouillard rouge (Riga, 1942). 
Épopée et avatars du film Brouillard rouge ...

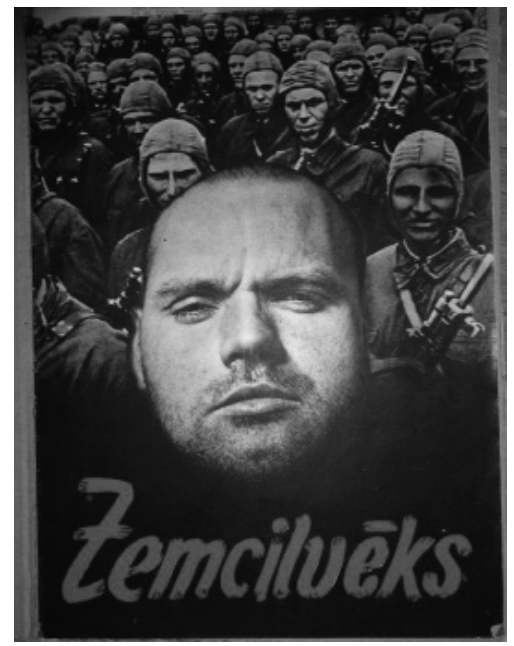

Fig.10. Page de couverture de l'album Sous-Hommes (Nordland Verlag, Berlin SW 11, 1942). Édition en langue lettone. Courtoisie du musée juif de Riga.

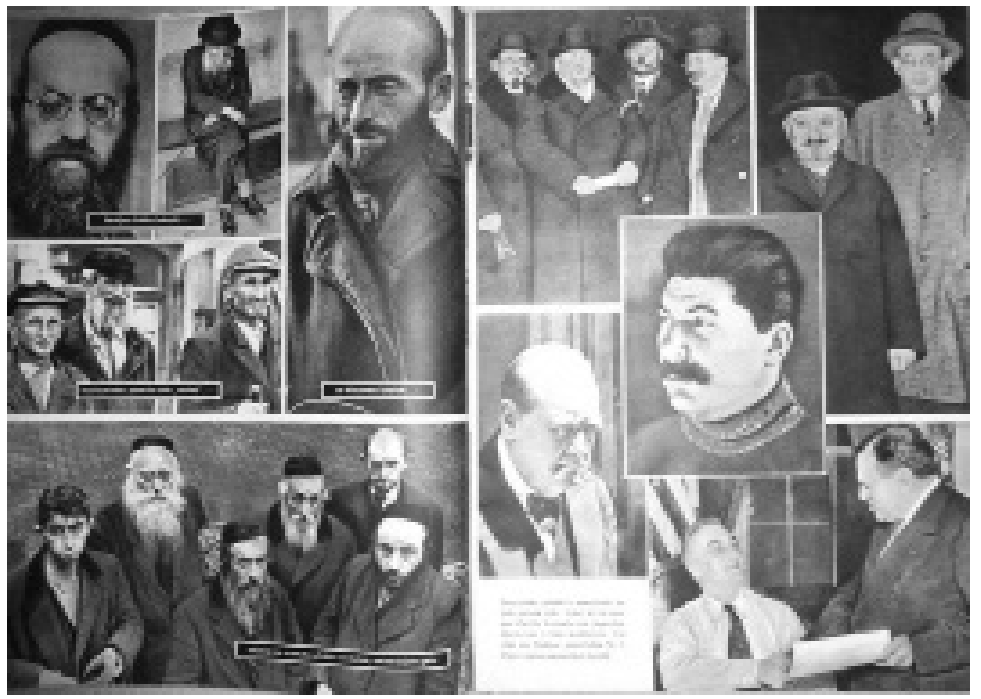

Fig. 11. 


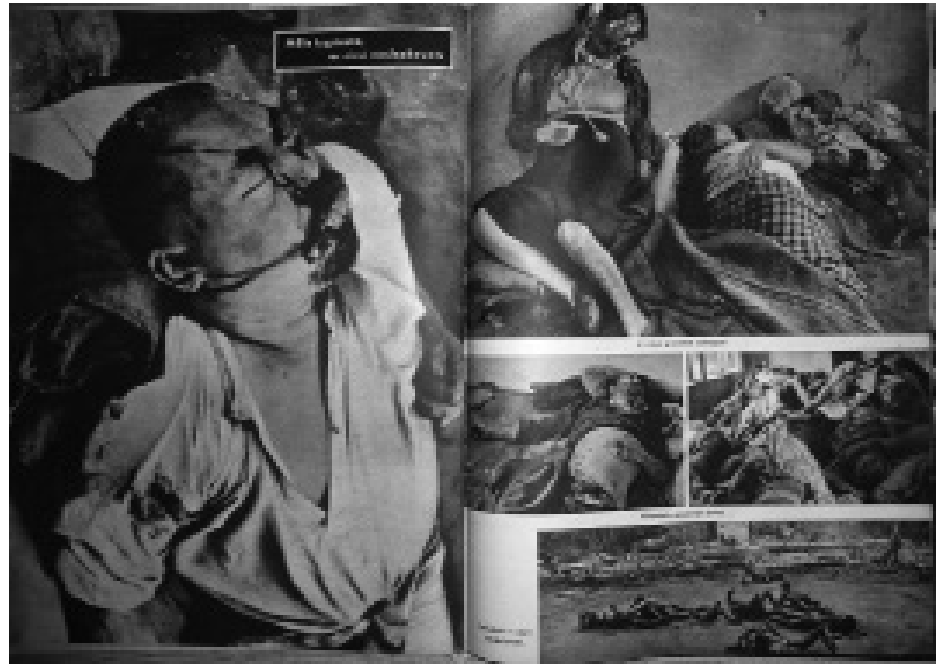

Fig. 12.
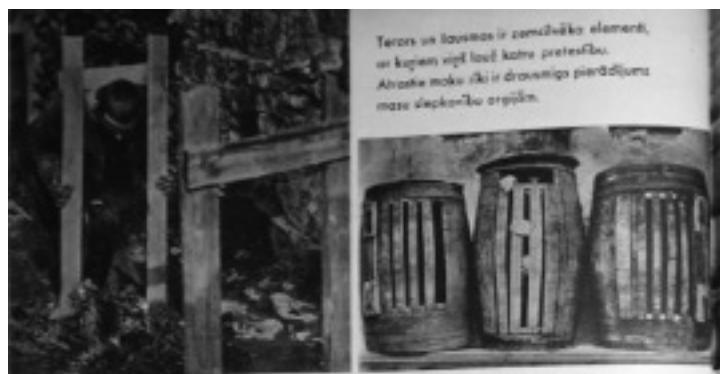

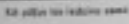

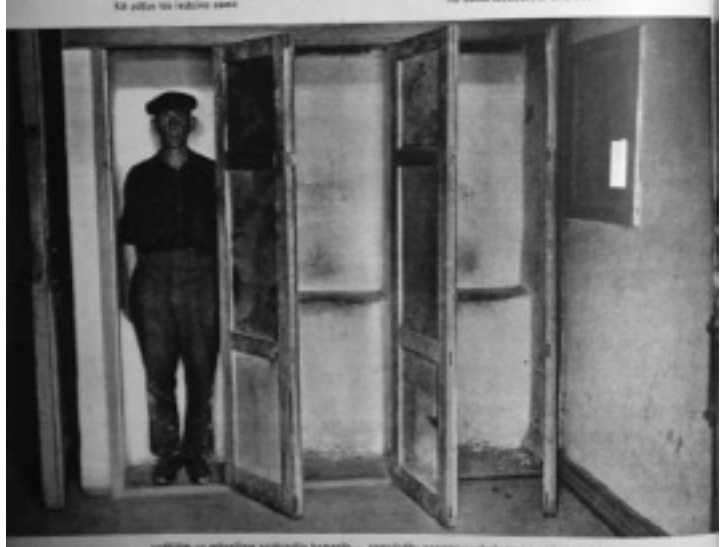

Fig. 11 à 13. Trois planches de Sous-Hommes. Courtoisie du Musée juif de Riga. 
Épopée et avatars du film Brouillard rouge ...

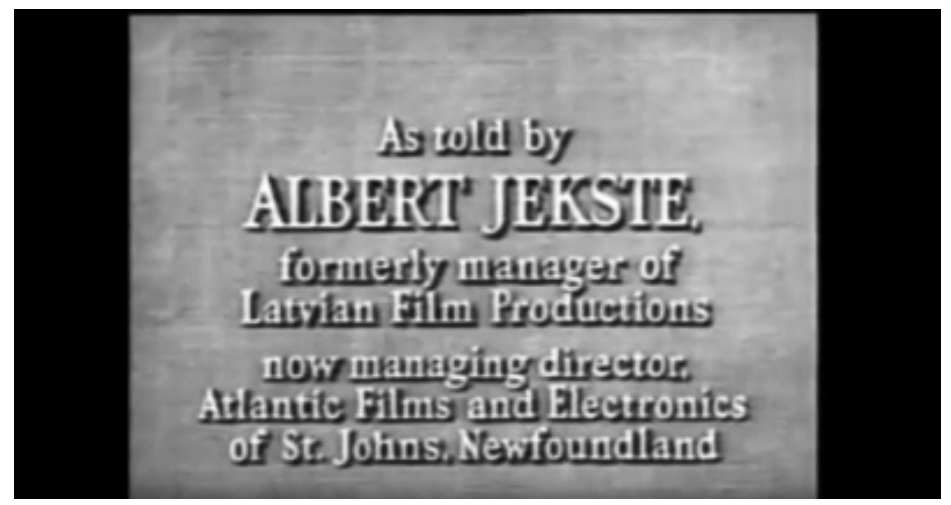

Fig.14.

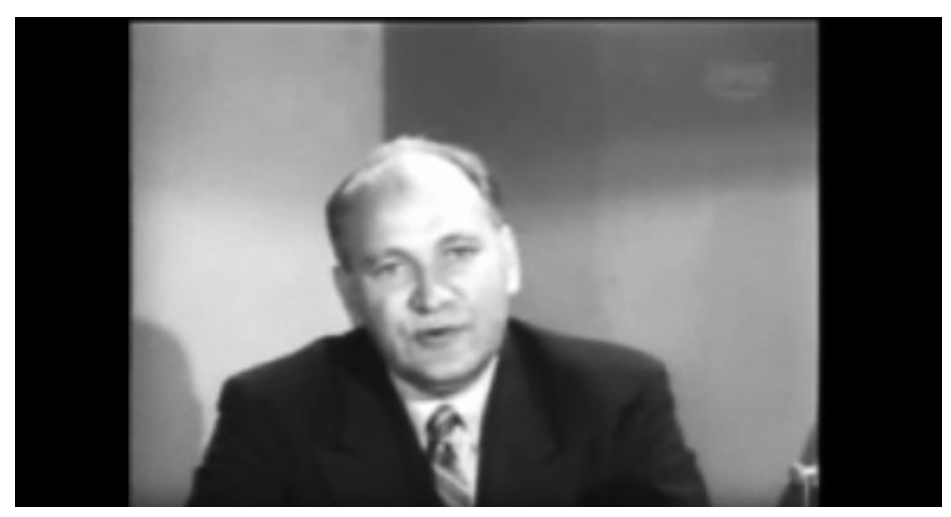

Fig.14 et 15. Captures d'écran de My Latvia. 